\title{
Assessment of Pilot Direct Contact Membrane Distillation Regeneration of Lithium Chloride Solution in Liquid Desiccant Air-conditioning Systems Using Computer Simulation
}

Hung Cong Duong ( $\nabla$ hungduongcong@gmail.com )

Le Quy Don Technical University https://orcid.org/0000-0003-4732-3440

Long Duc Nghiem

University of Technology Sydney

Ashley Joy Ansari

University of Wollongong

Thao Dinh Vu

Le Quy Don Technical Uinversity

Khai Manh Nguyen

Vietnam National University

\section{Research Article}

Keywords: membrane distillation (MD), direct contact membrane distillation (DCMD), polarisation effects, heat and mass transfer, liquid desiccant air-conditioning (LDAC), liquid desiccant regeneration

Posted Date: April 23rd, 2021

DOI: https://doi.org/10.21203/rs.3.rs-394757/v1

License: (c) (1) This work is licensed under a Creative Commons Attribution 4.0 International License.

Read Full License

Version of Record: A version of this preprint was published at Environmental Science and Pollution Research on August 5th, 2021. See the published version at https://doi.org/10.1007/s11356-021-157835 . 

lithium chloride solution in liquid desiccant air-conditioning systems using computer simulation

Submitted to

$20 *$ Corresponding author:

21 Hung Cong Duong, email: hungduongcong@gmail.com; Tel: +84 357593243 
22 Abstract: Membrane distillation (MD) has been increasingly explored for treatment of various 23 hyper saline waters, including lithium chloride $(\mathrm{LiCl})$ solutions used in liquid desiccant air24 conditioning (LDAC) systems. In this study, the regeneration of liquid desiccant $\mathrm{LiCl}$ solution by 25 a pilot direct contact membrane distillation (DCMD) process is assessed using computer 26 simulation. Unlike previous experimental investigations, the simulation allows to incorporate both 27 temperature and concentration polarisation effects in the analysis of heat and mass transfer through 28 the membrane, thus enabling the systematic assessment of the pilot DCMD regeneration of the $29 \mathrm{LiCl}$ solution. The simulation results demonstrate distinctive profiles of water flux, thermal 30 efficiency, and $\mathrm{LiCl}$ concentration along the membrane under co-current and counter-current flow 31 modes, and the pilot DCMD process under counter-current flow is superior to that under co-current 32 flow regarding the process thermal efficiency and $\mathrm{LiCl}$ concentration enrichment. Moreover, for 33 the pilot DCMD regeneration of $\mathrm{LiCl}$ solution under the counter-current flow, the feed inlet 34 temperature, $\mathrm{LiCl}$ concentration, and especially the membrane leaf length exert profound impacts 35 on the process performance: the process water flux halves from 12 to $6 \mathrm{~L} /\left(\mathrm{m}^{2} \cdot \mathrm{h}\right)$ while thermal 36 efficiency decreases by $20 \%$ from 0.46 to 0.37 when the membrane leaf length increases from 0.5 37 to $1.5 \mathrm{~m}$.

38 Keywords: membrane distillation (MD); direct contact membrane distillation (DCMD); 39 polarisation effects; heat and mass transfer, liquid desiccant air-conditioning (LDAC); liquid 40 desiccant regeneration. 


\section{Declarations}

\section{Ethics approval and consent to participate}

$44 \quad$ Not applicable

\section{Consent for publication}

$46 \quad$ Not applicable

\section{Availability of data and materials}

48 The datasets generated and/or analysed during the current study are not publicly available due

49 to regulations of the funding but are available from the corresponding author on reasonable request.

\section{Competing interests}

51 The authors declare the following financial interests/personal relationships which may be 52 considered as potential competing interests: Vietnam National Foundation for Science and 53 Technology Development (NAFOSTED); Le Quy Don Technical University; University of 54 Technology, Sydney

\section{$55 \quad$ Funding}

56 This research is funded by Vietnam National Foundation for Science and Technology

57 Development (NAFOSTED) under the grant number 105.08-2019.08.

\section{Authors' contributions}

59 HCD: Conceptualisation, Methodology, Software, Formal Analysis, Resources, Writing60 Original Draft;

61 LDN: Conceptualisation, Methodology, Review \& Editing

62 AJA: Methodology, Validation, Formal Analysis

63 TDV: Validation, Writing, Review \& Editing

64 KMN: Methodology, Validation, Formal Analysis, Review \& Editing 


\section{Introduction}

Membrane distillation (MD), a hybrid thermal-driven separation process, has been increasingly explored for treatment of various hyper saline waters due to its distinguishing attributes (Nguyen et al. 2018; Abdelkader et al. 2019; Duong et al. 2019). In the MD process, a hydrophobic microporous membrane is used to separate a saline water feed from a fresh distillate stream. Given its hydrophobic nature, the membrane retains liquid water on the feed side, but allows the transfer of water vapour through its pores to the other side, hence concentrating the feed water. The driving force for the transfer of water in the MD process is not the hydraulic and/or osmotic pressure difference but the water vapour pressure gradient induced by a temperature difference across the membrane. As a result, unlike pressure-driven membrane processes, MD is less subject to the salt concentration of the feed water, and hence it is workable with various hyper saline waters including concentrated brine from reverse osmosis (RO) desalination (Yan et al. 2017; Bindels et al. 2020), diluted draw solution from forward osmosis (FO) (Nguyen et al. 2018), and liquid desiccant solutions used in air-conditioning industry (Duong et al. 2019; Zhou et al. 2020; Liu et al. 2021). Because only water vapour and volatile compounds are allowed to permeate through its membrane, the MD process can achieve theoretically complete salt rejections, enabling the regeneration and/or recovery of valuable dissolved salts in saline waters. More importantly, as a thermal-driven separation technology, the MD process can be powered by low-grade waste heat or renewable solar thermal energy to reduce the process energy cost. Given these notable attributes, MD has emerged as an ideal candidate to be integrated into other process for treatment of hyper saline waters with improved energy efficiency. One notable example can be the integration of MD into the liquid desiccant air-conditioning (LDAC) process (Duong et al. 2017; Duong et al. 2018; Lefers et al. 2018; Zhou et al. 2020; Zhou et al. 2020).

LDAC is a potential game changer in advancing the air-conditioning industry to become greener and more energy-efficient (Gurubalan et al. 2019; Chen et al. 2020; Salikandi et al. 2021).

92 Currently, most conventional air-conditioning systems are based on the vapour compression 93 process, whereby the air is first dehumidified by deep cooling to dew point temperature to condense 94 moisture and then reheated to achieve a desired temperature. The deep cooling and the subsequent 95 reheating of the air waste energy, rendering the conventional air-conditioning systems energy-

96 inefficient (Modi and Shukla 2018; Duong et al. 2019). On the other hand, LDAC systems 
97 dehumidify and cool the air via the direct absorption of moisture into a liquid desiccant solution

98 (i.e. lithium chloride ( $\mathrm{LiCl}$ ) solution). The hygroscopic nature of the liquid desiccant solution drives

99 the moisture removal without the need for deep cooling and reheating the air; therefore, the energy

100 consumption of the LDAC systems is markedly reduced compared to that of the conventional

101 vapour-compression based air-conditioners (Gurubalan et al. 2019; Chen et al. 2020; Salikandi et

102 al. 2021).

103 Regeneration of liquid desiccant solution is a key step of the LDAC process (Duong et al. 2018;

104 Lefers et al. 2018; Zhou et al. 2020). The moisture holding capacity (i.e. hygroscopicity) of the

105 liquid desiccant solution depends on concentration and temperature. During the air dehumidification of the LDAC process, moisture absorption dilutes and warms the liquid desiccant solution, hence gradually reducing its hygroscopicity. To restore the liquid desiccant solution's hygroscopicity and hence the LDAC process's air dehumidification efficiency, the diluted (i.e. weak) liquid desiccant solution needs to be regenerated (i.e. reconcentrated and cooled) in a regenerator. Most current LDAC systems rely on thermal evaporation for the regeneration of liquid desiccant solutions (Cheng and Zhang 2013; Duong et al. 2019). This regeneration method involves heating the diluted liquid desiccant solution to a high temperature prior to spraying it in counter-

113 current flow with a hot air stream in a packed bed media (Lowenstein 2008; Cheng and Zhang 114 2013; Salikandi et al. 2021). The direct contact between the hot liquid desiccant solution and the 115 air stream inevitably leads to the carry-over of desiccant droplets in the air stream, which is 116 regarded as a vexing technical issue of the thermal evaporation regeneration method (Duong et al.

117 2019; Gurubalan et al. 2019; Chen et al. 2020; Salikandi et al. 2021). Moreover, high-temperature 118 heating required for the regeneration of liquid desiccant solution in the evaporation regenerator 119 primarily contributes to the energy consumption of the LDAC process. As a result, novel 120 regeneration methods that are resistant to desiccant carry-over and workable at mild temperature 121 are urgently needed for the realisation of LDAC systems. In this context, the MD process can be 122 tapped into given its complete salt rejection and workability with hyper saline waters at mild 123 temperature.

124 Previous experimental works have been conducted to prove the technical feasibility of MD for 125 the regeneration of liquid desiccant solutions used in the LDAC process (Duong et al. 2017; Duong 126 et al. 2018; Lefers et al. 2018; Zhou et al. 2019; Zhou et al. 2020; Zhou et al. 2020; Liu et al. 2021). 127 Most notably, Duong et al. (2017) experimentally investigated the direct contact membrane 
128 distillation (DCMD) regeneration of liquid desiccant $\mathrm{LiCl}$ solutions and proved that the DCMD

129 process could regenerate the liquid desiccant $\mathrm{LiCl}$ solution of $29 \%$ without any issue of desiccant

130 carry-over at the feed temperature of $65{ }^{\circ} \mathrm{C}$. Zhou et al. (2020) systematically examined the

131 performance of vacuum membrane distillation (VMD) during the regeneration of $\mathrm{LiCl}$ solution.

132 Despite using short hollow fibre membranes (i.e. $0.52 \mathrm{~m}$ in length), the lab-scale VMD process

133 could increase the concentration of the $\mathrm{LiCl} 20 \%$ solution by $0.2 \%$ when operating in the single-

134 pass mode at the feed temperature of $65^{\circ} \mathrm{C}$ (Zhou et al. 2020). Particularly, the experimental results

135 demonstrated the profound impacts of $\mathrm{LiCl}$ solution temperature and membrane length on the 136 regeneration performance of the VMD process.

137 Previous lab-scale experimental works have demonstrated the viability of MD regeneration of 138 liquid desiccant $\mathrm{LiCl}$ solutions. It is, however, necessary to underline that there have been no 139 experimental investigations or simulation studies on pilot or large-scale MD regeneration of liquid 140 desiccant solutions, despite a great number of pilot MD processes experimentally demonstrated 141 and simulated for seawater desalination applications (Hitsov et al. 2015; Dong et al. 2017; Duong 142 et al. 2017; Andrés-Mañas et al. 2018; Andrés-Mañas et al. 2020). To facilitate the realisation of 143 MD regeneration of liquid desiccant solutions, pilot or large-scale studies are of vital importance. 144 Therefore, this study aims to assess a pilot MD process for regeneration of liquid desiccant $\mathrm{LiCl}$ 145 solution with the aid of computer simulation. Unlike previous simulations of pilot seawater MD 146 desalination, the pilot DCMD simulation reported in this study incorporates the influences of the

$147 \mathrm{LiCl}$ solution hyper salinity and the negative effects of polarisation phenomena, particularly the 148 concentration polarisation, on the process mass and heat transfer. Given its flexibility and high 149 accuracy, the simulation package offers useful means to elucidate the mass and heat transfer inside 150 the pilot DCMD membrane module, thus allowing to elaborate the impacts of process operating 151 conditions and membrane module specifications on the process performance during the 152 regeneration of liquid desiccant $\mathrm{LiCl}$ solution.

\section{2. Heat and mass transfer calculations and simulation approaches}

\section{2.1. Heat and mass transfer calculations}

155 During the DCMD regeneration of $\mathrm{LiCl}$ solution, the transfer of water (i.e. mass transfer) occurs 156 simultaneously with the heat flux through the membrane. While the mass transfer directly controls 
the moisture desorption and hence the regeneration of the $\mathrm{LiCl}$ solution, the heat flux through the membrane is undesirable as it reduces the driving force of the regeneration process. The mass transfer through the membrane is proportional to the water vapour pressure difference between the two sides of the membrane, and is expressed as (Alkhudhiri et al. 2012):

161

$$
J=C_{m} \times\left(P_{m . f}-P_{m . d}\right)
$$

162 where $J$ is water flux $\left(\mathrm{kg} /\left(\mathrm{m}^{2} \cdot \mathrm{h}\right)\right) ; C_{m}$ is the membrane mass transfer coefficient $\left(\mathrm{kg} /\left(\mathrm{m}^{2} \cdot \mathrm{h} \cdot \mathrm{Pa}\right)\right)$; and $163 P_{m . f}$ and $P_{m . d}$ are the water vapour pressures (Pa) at the feed and distillate membrane surfaces, 164 respectively. $C_{m}$, a function of membrane characteristics and process operating conditions, is 165 calculated as below (Alkhudhiri et al. 2012):

$$
C_{m}=\left[\frac{3}{2} \frac{\tau \delta}{\varepsilon r}\left(\frac{\pi R T}{8 M}\right)^{1 / 2}+\frac{\tau \delta}{\varepsilon} \frac{P_{a}}{P D} \frac{R T}{M}\right]^{-1}
$$

167 where $\delta, \varepsilon, \tau$, and $r$ are the membrane thickness (m), porosity (dimensionless), pore tortuosity 168 (dimensionless), and pore radius (m), respectively; $M$ is the molecular weight of water ( $\mathrm{kg} / \mathrm{mol}) ; R$ 169 is the gas constant (i.e. $8.314 \mathrm{~J} /(\mathrm{mol} \cdot \mathrm{K})) ; T$ is the mean water vapour temperature (K) inside the 170 membrane pore; $P$ and $P_{a}$ are the total pressure and the air partial pressure $(\mathrm{Pa})$ inside the membrane 171 pore; and $D$ is the water diffusion coefficient $\left(\mathrm{m}^{2} / \mathrm{s}\right)$. The distillate water vapour pressure at the 172 membrane surface (i.e. $P_{m . d}$ ) can be calculated using the Antoine equation (Alkhudhiri et al. 2012):

$173 \quad P_{m . d}=\exp \left(23.1964-\frac{3816.44}{T_{m . d}-46.13}\right)$

174 where $T_{m . d}$ is the distillate temperature $(\mathrm{K})$ at the membrane surface. On the other hand, the 175 calculation of water vapour pressure at the feed membrane surface (i.e. $\left.P_{m . f}\right)$ involves complex 176 functions of $\mathrm{LiCl}$ solution concentration and temperature at the feed membrane surface (e.g. $S_{m . f}$ 177 and $\left.T_{m . f}\right)$. More details of the water vapour pressure calculation of the $\mathrm{LiCl}$ solution at high 178 concentrations are provided elsewhere (Conde 2004; Duong et al. 2020).

179 During the DCMD process of the $\mathrm{LiCl}$ solution, in tandem with water vapour flux, heat is 180 transferred from the feed to the distillate via conduction through the membrane matrix and the 
181 latent heat associated with the transferred water vapour. The heat flux $(Q)$ through the membrane 182 is described as (Alkhudhiri et al. 2012):

183

$$
Q=\frac{k_{m}}{\delta}\left(T_{m \cdot f}-T_{m \cdot d}\right)+J \Delta H_{v}
$$

where $Q$ is in $\mathrm{kJ} /\left(\mathrm{m}^{2} \cdot \mathrm{h}\right) ; k_{m}$ is the membrane thermal conductivity $(\mathrm{W} /(\mathrm{m} \cdot \mathrm{K}))$; and $\Delta H_{v}$ is the latent heat of evaporation of water $(\mathrm{kJ} / \mathrm{kg})$. The membrane thermal conductivity is a function of polymer thermal conductivity $\left(k_{s}\right)$ and gas thermal conductivity $\left(k_{g}\right)$, expressed as (Alkhudhiri et al. 2012):

$$
k_{m}=\left[\frac{\varepsilon}{k_{g}}+\frac{1-\varepsilon}{k_{s}}\right]^{-1}
$$

The latent heat of water evaporation (i.e. $\Delta H_{v}$ ) is a function of the mean water vapour temperature inside the membrane pore, and is calculated as (Alkhudhiri et al. 2012):

$$
\Delta H_{v}=1.7535 T+2024.3
$$

Water flux calculation using the membrane mass transfer coefficient $\left(C_{m}\right)$ in equation (1) involves temperature and salt concentration at the membrane surfaces (e.g. $T_{m . f}, T_{m . d}$, and $S_{m . f}$ ). During the DCMD process of $\mathrm{LiCl}$ solutions, polarisation effects cause the temperature and salt concentration at the membrane surfaces different to those in the bulk feed and distillate streams (e.g. $T_{b . f}, T_{b . d}$, and $S_{b . f}$ ) (Kuang et al. 2019; Anvari et al. 2020). While the bulk temperature and salt concentration of the feed and distillate streams can be experimentally measured, the measurements of these parameters at the membrane surfaces require complex instruments and impractical membrane module designs (Kuang et al. 2019; Lokare et al. 2019). In this context, several studies have utilised the process mass transfer coefficient (i.e. $K_{m}$ ) together with the bulk feed and distillate temperature and salt concentration for water flux calculation. This water flux calculation is more practical when involving the measurable thermodynamic properties of the bulk feed and distillate; however, it fails to incorporate polarisation effects, particularly concentration polarisation,

203 resulting in considerable deviations between the calculated and experimentally measured water 204 flux (Duong et al. 2017; Duong et al. 2018). The computer model developed for the simulation of 205 
polarisation effect in water flux calculation, but deliberately neglects the concentration polarisation effect given the negligible impacts of seawater salinity on water flux. For the pilot DCMD regeneration of liquid desiccant $\mathrm{LiCl}$ solutions, the hyper salinity of the feed exerts profound influences on water flux; therefore, the concentration polarisation effect must be incorporated in water flux calculation together with the temperature polarisation effect.

211 The simulation model built for this study incorporates both temperature and concentration 212 polarisation effects in water flux calculation and heat transfer analysis. Initially, water flux $(J)$ is 213 calculated using the bulk thermodynamic properties of the feed and distillate, then the temperature 214 and $\mathrm{LiCl}$ concentration at the feed and distillate membrane surfaces (i.e. $T_{m . f}, S_{m . f}$, and $T_{m . d}$ ) are 215 calculated as below (Khayet et al. 2004; Hitsov et al. 2015):

$$
T_{m . f}=\frac{T_{b . f} h_{f}+h_{m}\left(T_{b . d}+T_{b . f} \frac{h_{f}}{h_{d}}\right)-J \Delta H_{v}}{h_{f}\left(1+\frac{h_{m}}{h_{d}}\right)+h_{m}}
$$

$$
\begin{aligned}
& T_{m . d}=\frac{T_{b . d} h_{d}+h_{m}\left(T_{b . f}+T_{b . d} \frac{h_{d}}{h_{f}}\right)+J \Delta H_{v}}{h_{d}\left(1+\frac{h_{m}}{h_{f}}\right)+h_{m}} \\
& S_{m . f}=S_{b . f} \times \exp \left(\frac{J}{\rho \times k}\right)
\end{aligned}
$$

219 where $h_{m}, h_{f}$, and $h_{d}$ are respectively the heat transfer coefficient across the membrane and in the 220 feed and distillate thermal boundary layers; $\rho$ and $k$ are the density and the water transfer coefficient 221 of the $\mathrm{LiCl}$ solution feed. The heat transfer coefficient across the membrane $\left(h_{m}\right)$ is dependent on 222 the membrane thermal conductivity $\left(k_{m}\right)$ and the membrane thickness $(\delta)$, while the calculations of 223 the heat transfer coefficients in the feed and distillate boundary layers ( $h_{f}$ and $h_{d}$ ) involve Nusselt 224 number $(\mathrm{Nu})$, Reynolds number $(\mathrm{Re})$, and Prandtl number $(\mathrm{Pr})$ using the fluid thermodynamic properties (e.g. density, dynamic viscosity, specific heat capacity, and cross flow velocity) and the hydraulic diameter of the feed and distillate channels. Empirical equations for the calculations of 
the thermodynamic properties of the $\mathrm{LiCl}$ solution feed and the distillate are provided in (Conde 2004). The calculated $T_{m . f}, T_{m . d}$, and $S_{m . f}$ are then used for the calculation of $J$ in equation (1). The new calculated value is now assigned to $J$ in the calculation of new $T_{m . f}, T_{m . d}$, and $S_{m . f}$ in the equations (7-9). This calculation process is iterated until the difference between the two consecutive values of $J$ is negligible.

Thermal efficiency is an important aspect of the DCMD process of $\mathrm{LiCl}$ solutions as the regeneration step contributes over three quarters of the energy consumption of LDAC systems, and the energy consumption of the DCMD process is primarily attributed to thermal energy required for heating the feed stream. The thermal efficiency (II) of the DCMD process is evaluated using the following equation (Alkhudhiri et al. 2012):

$$
\Pi=\frac{J \Delta H_{v}}{J \Delta H_{v}+\frac{k_{m}}{\delta}\left(T_{m . f}-T_{m . d}\right)}
$$

Besides thermal efficiency, the specific thermal energy consumption (i.e. STEC) of the DCMD process of the $\mathrm{LiCl}$ solution is also assessed. STEC is the heating required to increase the weight concentration of one volume unit of $\mathrm{LiCl}$ solution feed by $1 \%$, and can be calculated as:

$$
S T E C=\frac{m_{f . i n} \times C_{p} \times\left(T_{f . i n}-25\right)}{3.6 \times 10^{3} \times \Delta S \times V_{f . \text { in }}}
$$

242 where $S T E C$ is in $\mathrm{kWh} /\left(\% \cdot \mathrm{m}^{3}\right) ; m_{f i n}$ is the feed inlet mass flow rate $(\mathrm{kg} / \mathrm{h}) ; C_{p}$ is the specific heat 243 capacity of the $\mathrm{LiCl}$ solution feed $\left(\mathrm{kJ} /\left(\mathrm{kg} \cdot{ }^{\circ} \mathrm{C}\right)\right) ; T_{\text {fin }}$ is the feed inlet temperature of the DCMD 244 process; $\Delta S$ is the $\mathrm{LiCl}$ concentration enrichment (i.e. the difference between the $\mathrm{LiCl}$ concentration 245 at the outlet and the inlet of the feed channel) (\%); and $V_{\text {f.in }}$ is the feed inlet volume flow rate $\left(\mathrm{m}^{3} / \mathrm{h}\right)$. 246 It is necessary to note that while STEC offers a practical indicator for the DCMD process energy 247 efficiency, $\Pi$ demonstrates the proportion of the useful heat (i.e. that is associated with the transfer 248 of water) to the total heat transfer from the feed to the distillate along the membrane leaf inside the 249 DCMD membrane module. Moreover, the calculation of STEC for the DCMD process in this study 250 differs from that normally reported for seawater MD desalination applications because the main 251 product of the DCMD process in this study is the concentrated $\mathrm{LiCl}$ solution but not fresh water as 252 for seawater desalination. 


\subsection{Simulation approach}

254 The simulation package used in this study is developed based on the descriptive mass and heat 255 transfer (DMHT) model that has been validated and reported in a previous study by Duong et al. 256 (2020). One notable feature of this simulation package is the inclusion of both temperature and 257 concentration polarisation effects in the mass and heat transfer analyses, and it allows for the 258 simulation of the DCMD process of the $\mathrm{LiCl}$ solution under two flow modes: co-current and 259 counter-current flow (Fig. 1). Details about the DMHT model and the calculation of heat and mass 260 flux through each membrane area under the two flow modes can be found in the previous study by 261 Duong et al. (2020).
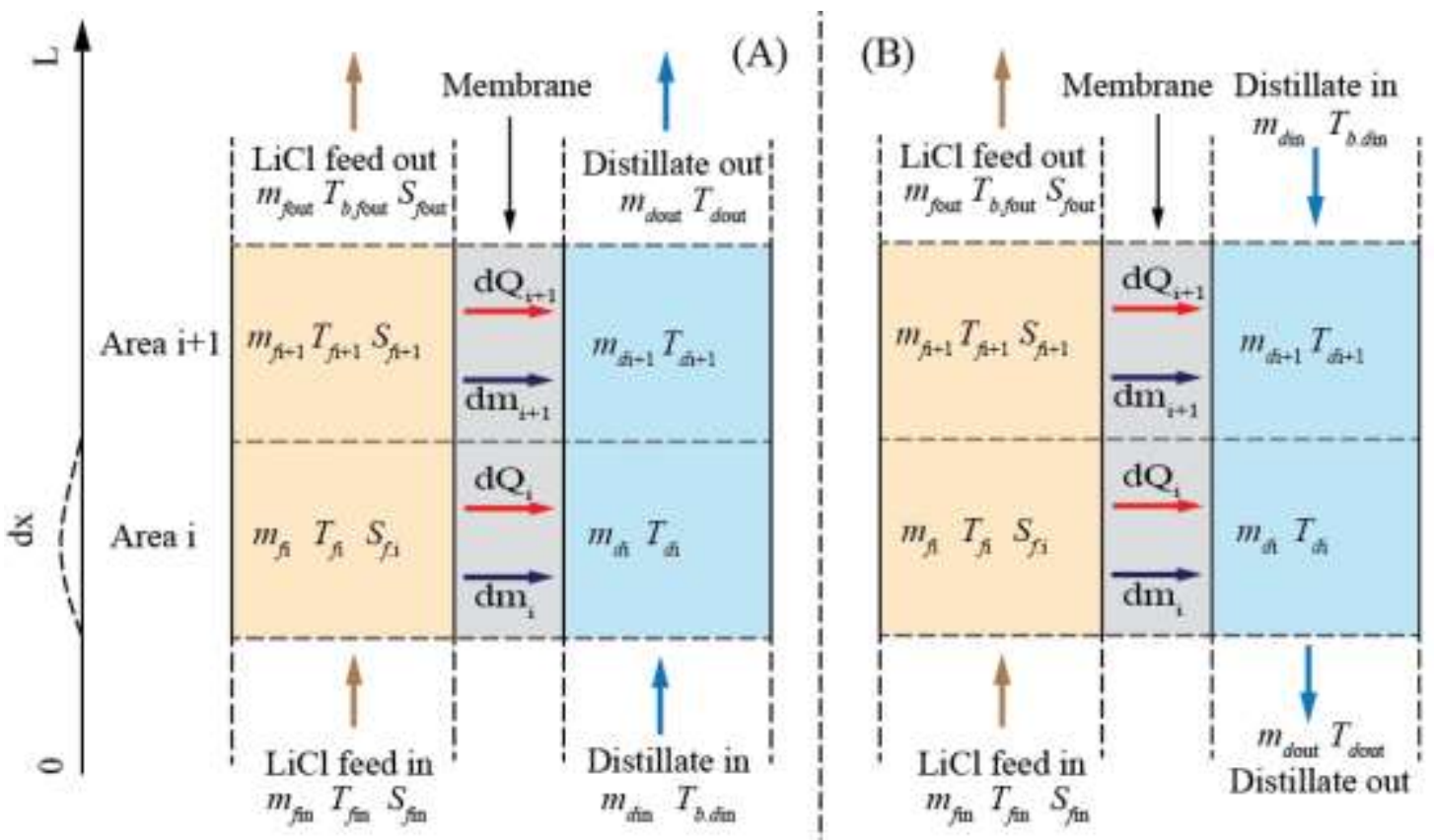

Fig. 1. Schematic diagram of two incremental membrane areas along the DCMD module under the (A) co-current and (B) counter-current flow mode.

The calculation algorithms of the DCMD process with the $\mathrm{LiCl}$ solution feed are illustrated in Fig. 2 and Fig. 3 for co-current and counter-current flow mode, respectively. The inputs of the calculation algorithms are the temperature, concentration, and mass flow rate of the $\mathrm{LiCl}$ solution feed and distillate respectively at the feed and distillate inlets (e.g. $T_{\text {fin }}, S_{\text {f.in }}, m_{\text {f.in }}, T_{\text {d.in }}$, and $m_{\text {d.in }}$ ). The calculation starts from the feed inlet end (i.e. $x_{0}=0$ ) and finishes at the feed outlet end (i.e. $x_{n}$ $=L)$ of the DCMD module. For co-current flow, the initial parameters of the feed and distillate 
271 streams are readily available. On the other hand, for counter-current flow, initial guesses of the 272 mass flow and temperature of the distillate at the outlet (i.e. $m_{\text {d.out }}$ and $T_{\text {d.out }}$ ) are required (Fig. 3).

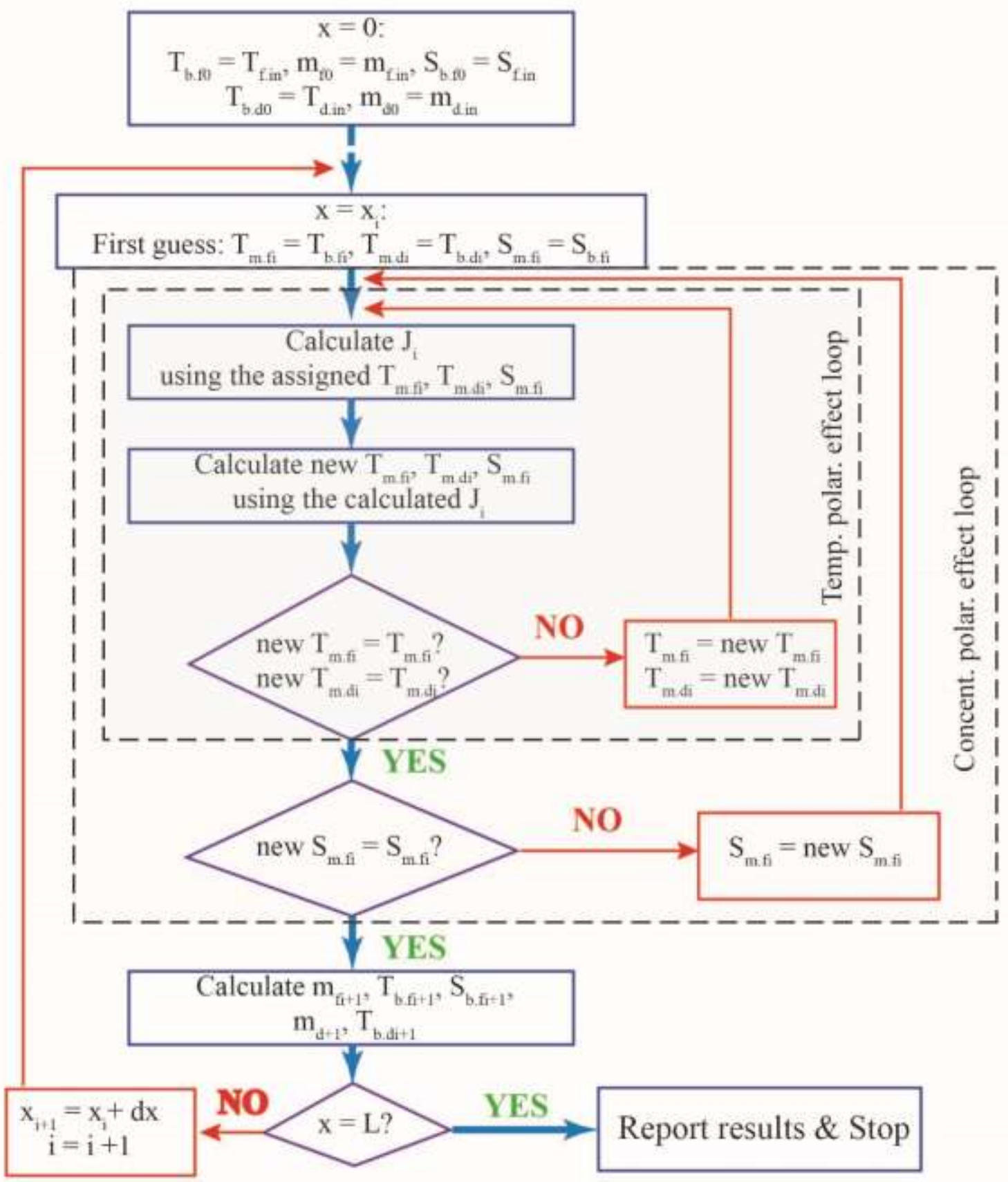

Fig. 2. Calculation algorithm of the DCMD simulation for co-current flow. 


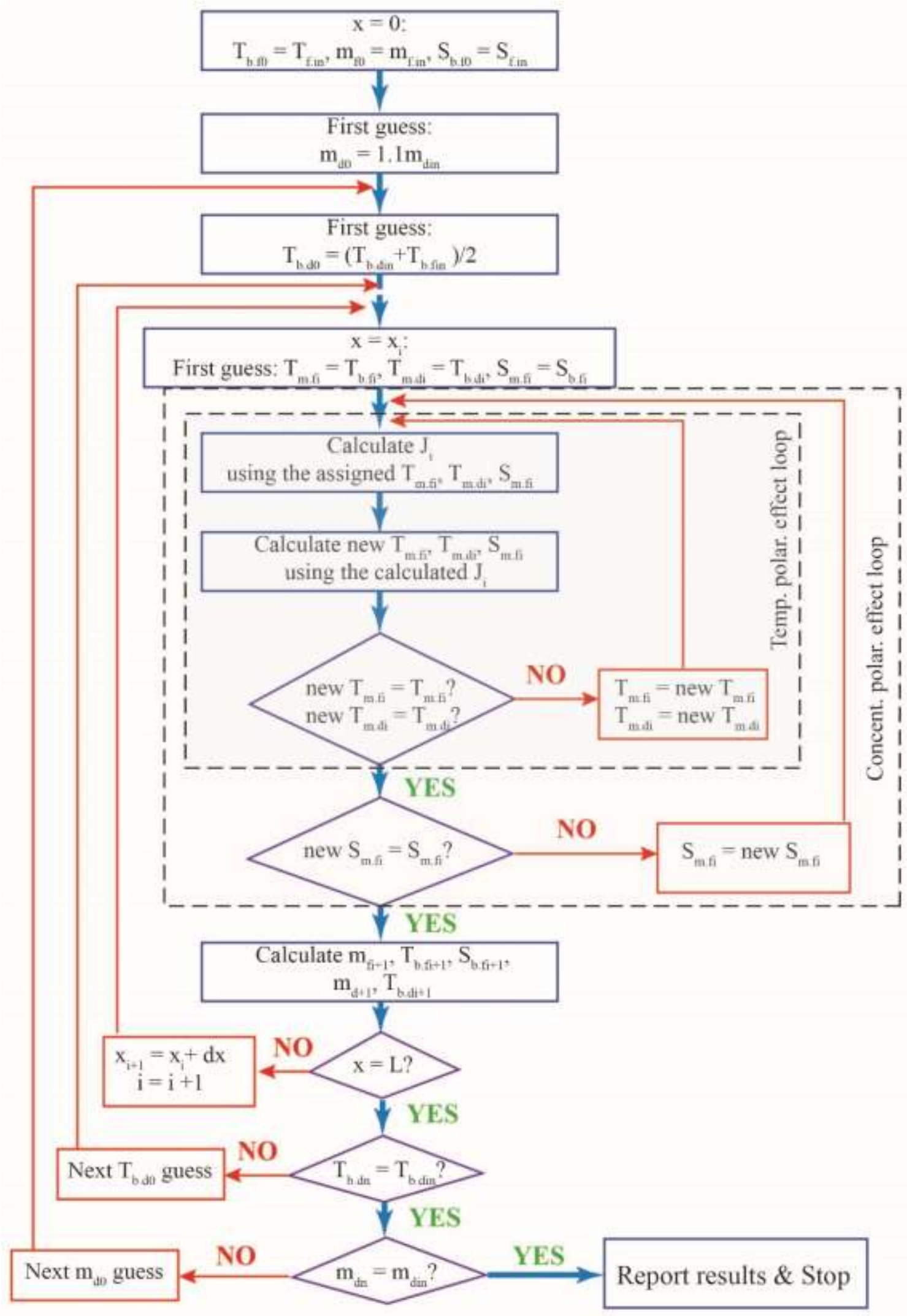

Fig. 3. Calculation algorithm of the DCMD simulation for counter-current flow. 
The specifications of the membrane leaf and feed and distillate channels of the pilot DCMD membrane module provided by AquaStill (Sittard, The Netherlands) (Hitsov et al. 2017) were used for the simulation in this study. These specifications include membrane pore radius, membrane porosity, membrane thickness, feed and distillate channel width and depth, and the membrane leaf length. Unless otherwise stated, their default values are provided in Table 1. The pilot DCMD membrane module used in (Hitsov et al. 2017) had six feed and six distillate channels, but they were parallel. Thus, for simplicity the pilot DCMD membrane module simulated in this study is composed of one feed and one distillate chanells with the same specifications.

Table 1. Specifications of the membrane leaf and flow channels of the pilot DCMD membrane 286 module

\begin{tabular}{ll}
\hline Membrane specifications & \\
Pore radius $(\mu \mathrm{m})$ & 0.15 \\
Membrane porosity $(-)$ & 0.76 \\
Membrane thickness $(\mu \mathrm{m})$ & 92 \\
Feed and distillate channels & \\
Channel width $(\mathrm{m})$ & 0.4 \\
Channel depth $(\mathrm{m})$ & 0.002 \\
Channel length $(\mathrm{m})$ & 1.5 \\
\hline
\end{tabular}

\section{Results and discussions}

\subsection{Mass and heat transfer through the membrane inside the module}

In the pilot DCMD regeneration of liquid desiccant $\mathrm{LiCl}$ solution, the flow mode exerts decisive influence on the heat and mass transfer through the membrane. As demonstrated in Fig. 4, cocurrent and counter-current modes result in two different feed and distillate temperatures and water flux profiles inside the membrane module. Under the co-current flow mode, from the inlet to the outlet of the membrane module the membrane surface feed temperature $\left(T_{m . f}\right)$ declines while the membrane surface distillate temperature $\left(T_{m . d}\right)$ increases due to heat transferred from the feed to the distillate, leading to a decrease in the transmembrane water temperature difference (i.e. $\Delta T_{m}$ ) (Fig. 4A). This decreased $\Delta T_{m}$ together with the increase in the $\mathrm{LiCl}$ concentration along the membrane results in a rapid decline in local water flux $(J)$ inside the membrane module from the inlet to the outlet. Moreover, it is noteworthy that after the membrane length of $0.9 \mathrm{~m}$, negative water flux is observed despite the positive $\Delta T_{m}\left(>10^{\circ} \mathrm{C}\right)$ (Fig. 4A). This finding confirms that the 
300 actual driving force for water transfer through the membrane in MD is the transmembrane water 301 vapour pressure (i.e. $\left.\Delta P_{m}\right)$, not the transmembrane water temperature difference $\left(\Delta T_{m}\right)$. After the 302 membrane length of $0.9 \mathrm{~m}, T_{m . f}$ remains markedly higher than $T_{m . d}$; however, the water vapour 303 pressure at the feed membrane surface is lower than that at the distillate membrane surface due to 304 the hyper salinity of the $\mathrm{LiCl}$ solution. As a result, reverse water flux from the distillate to the $\mathrm{LiCl}$ 305 solution feed occurs after the membrane length of $0.9 \mathrm{~m}$ (Fig. 4A).

306 On the other hand, the feed and distillate temperatures at the membrane surfaces and in the bulk 307 streams linearly decrease from the feed inlet to the feed outlet of the membrane module under the 308 counter-current mode (Fig. 4B). Although the temperature difference between the feed and 309 distillate membrane surfaces $\left(\Delta T_{m}\right)$ remains largely constant along the membrane leaf, the local 310 water flux markedly declines from the feed inlet to the feed outlet. The declining water flux along 311 the membrane module under counter-current mode has been elucidated in the previous study by 312 Duong et al. (2020) using a lab-scale membrane module. It is noteworthy that the local water flux 313 declines at a higher rate near the feed inlet than toward the feed outlet due to the exponential 314 relation between the water vapour pressure and the temperature of solutions (Fig. 4B).

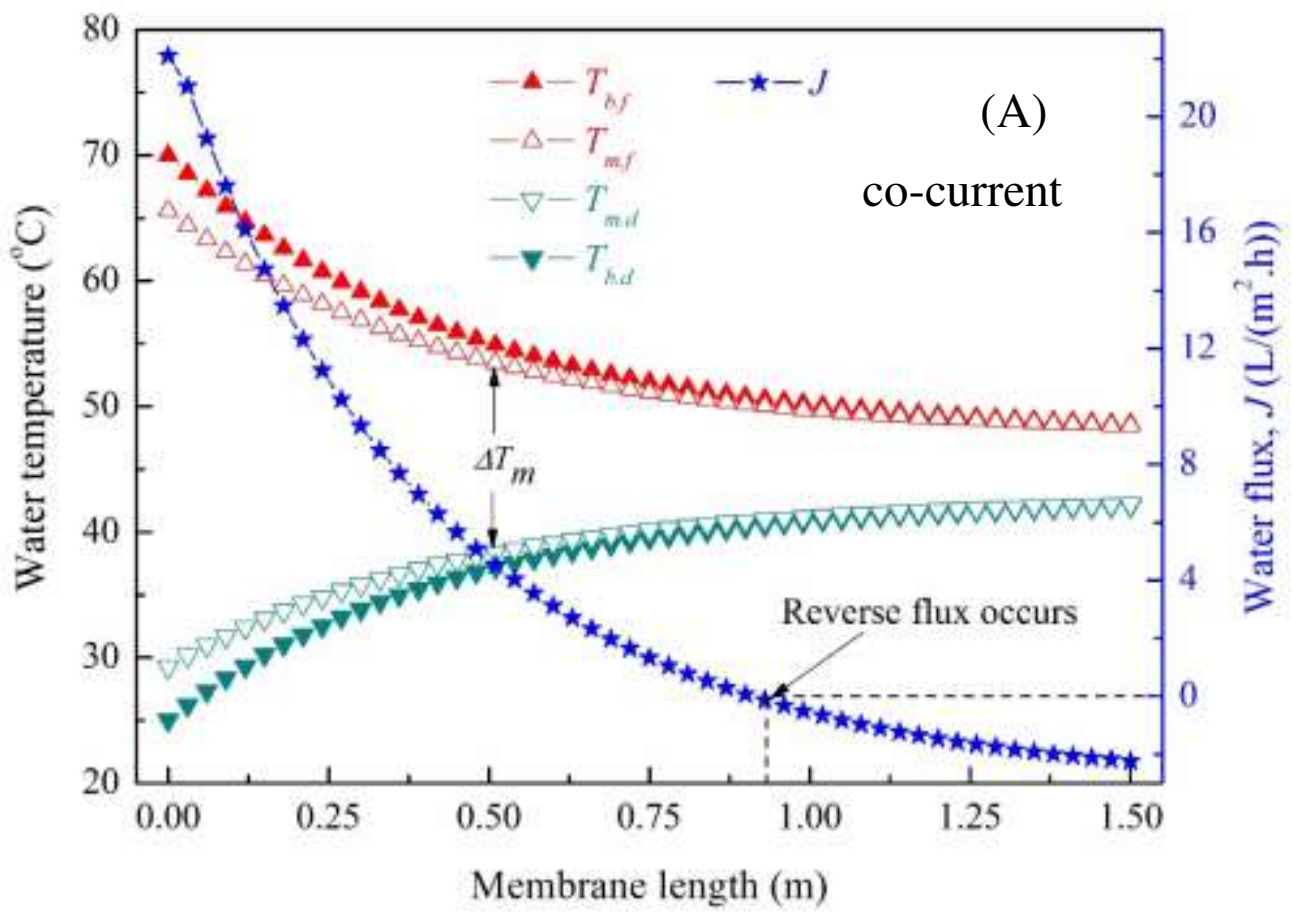




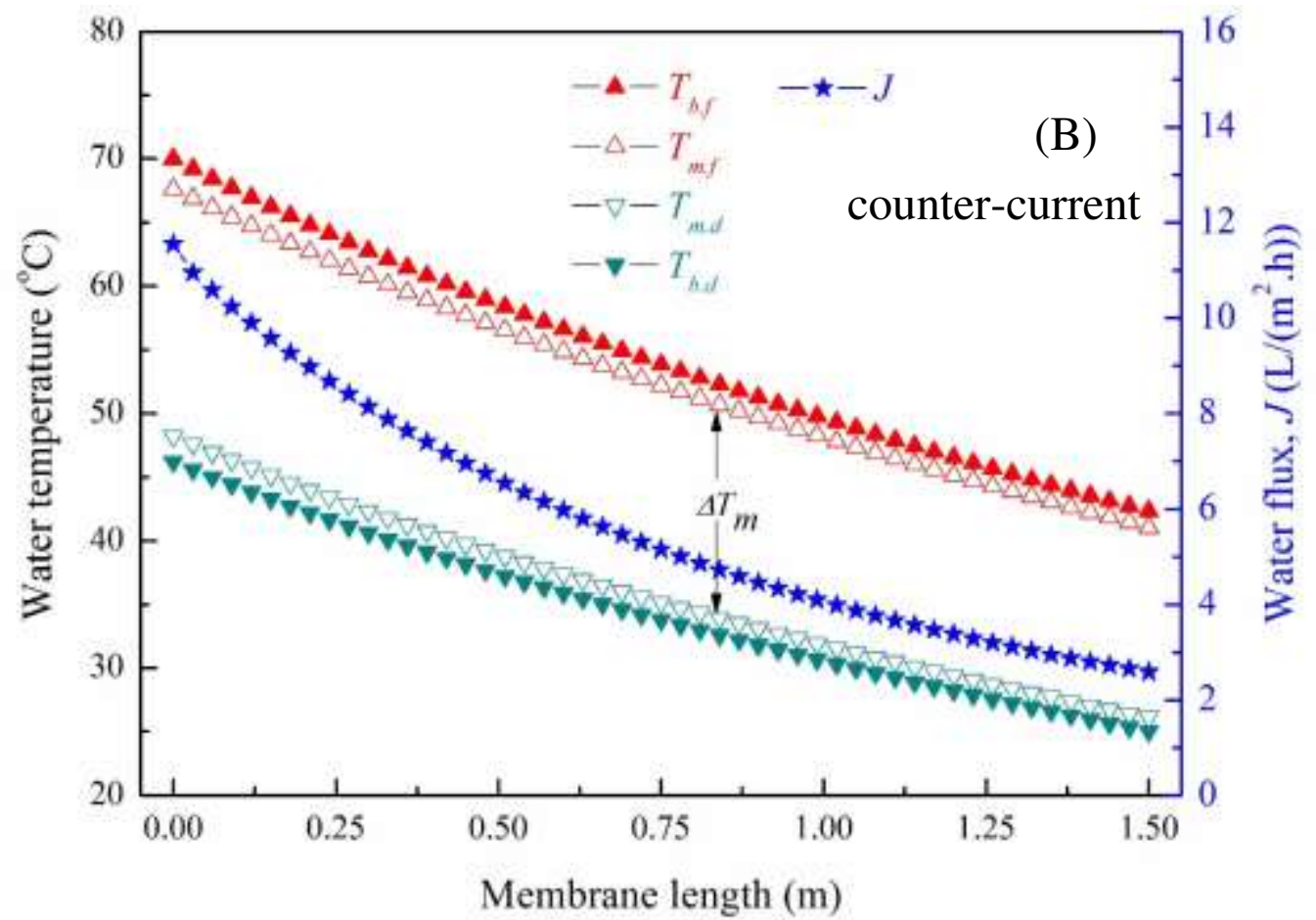

Fig. 4. Feed and distillate temperature at the membrane surfaces and in the bulk streams and water flux along the membrane inside the module during the DCMD regeneration of the $\mathrm{LiCl}$ $20 \%$ solution under (A) co-current and (B) counter-current flow. Operating conditions: feed inlet temperature $\left(T_{\text {f.in }}\right)=70^{\circ} \mathrm{C}$, distillate inlet temperature $T_{\text {d.in }}=25^{\circ} \mathrm{C}$, feed and distillate inlet circulation rate $F_{\text {fin }}=F_{\text {d.in }}=250 \mathrm{~L} / \mathrm{h}$.

The discrepancy in local water flux inside the membrane module under the two operation modes results in noticeably different profiles of thermal efficiency and the $\mathrm{LiCl}$ solution concentration (Fig. 5). The thermal efficiency of the DCMD process with the $\mathrm{LiCl} 20 \%$ solution feed under both operation modes is mostly below 0.5 . This means that during the DCMD regeneration of the $\mathrm{LiCl}$ $20 \%$ solution feed using the pilot system, more than half of the heat transfer from the feed to the distillate is due to the heat conduction through the membrane and is deemed the heat loss. Furthermore, thermal efficiency under co-current mode is discernibly lower than that under the counter-current mode, demonstrating that the counter-current operation is more beneficial to the pilot DCMD regeneration of $\mathrm{LiCl}$ solution with respect to thermal efficiency. It is important to stress that previous experimental studies on lab-scale DCMD regeneration of liquid desiccant $\mathrm{LiCl}$ solutions have not investigated the process thermal efficiency.

The bulk $\mathrm{LiCl}$ concentration (i.e. $S_{b . f}$ ) profiles along the membrane leaf under the two flow modes also clearly differ (Fig. 5). Under the co-current flow, from the feed inlet the $\mathrm{LiCl}$ concentration steadily increases and maximizes at the membrane length of $0.9 \mathrm{~m}$ before gradually 
334 decreasing toward the feed outlet (i.e. $1.5 \mathrm{~m}$ ). On the other hand, the $\mathrm{LiCl}$ concentration under the 335 counter-current mode progressively rises from the feed inlet to the feed outlet (Fig. 5). Indeed, 336 these $\mathrm{LiCl}$ concentration profiles are consistent with the water flux profiles shown in Fig. 4. The 337 decreased $\mathrm{LiCl}$ concentration under the co-current flow after the membrane length of $0.9 \mathrm{~m}$ is due 338 to the negative water flux (Fig. 4A). Moreover, the $\mathrm{LiCl}$ concentration at the feed outlet under the counter-current flow is noticeably higher than that under the co-current mode. This also manifests

340 the advantage of the counter-current operation over the co-current one for the pilot DCMD 341 regeneration of $\mathrm{LiCl}$ solutions.

342 The analysis of heat and mass transfer through the membrane inside the module has revealed 343 the superiority of the counter-current to the co-current mode during the pilot DCMD regeneration 344 of the liquid desiccant $\mathrm{LiCl}$ solution. Thus, the counter-current mode is selected for further 345 investigations on the influences of the operating conditions and membrane length on the pilot 346 DCMD process performance discussed in the next section.

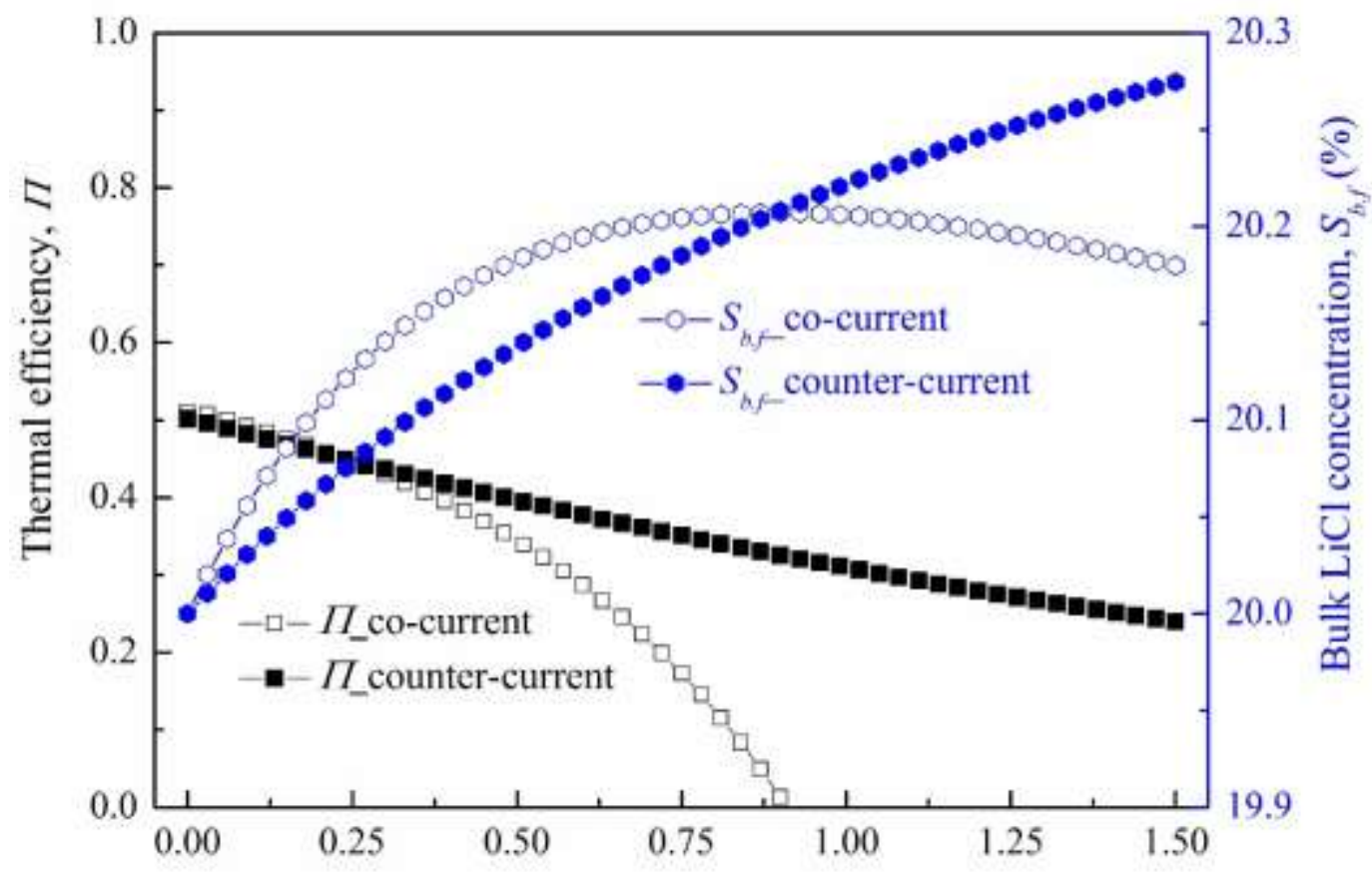

\section{Membrane length $(\mathrm{m})$}

Fig. 5. Thermal efficiency and the bulk $\mathrm{LiCl}$ concentration along the membrane inside the module during the DCMD regeneration of the $\mathrm{LiCl} 20 \%$ solution under co-current and countercurrent flow. Operating conditions: feed inlet temperature $\left(T_{\text {f.in }}\right)=70^{\circ} \mathrm{C}$, distillate inlet temperature $T_{\text {d.in }}=25^{\circ} \mathrm{C}$, feed and distillate inlet circulation rate $F_{\text {f.in }}=F_{\text {d.in }}=250 \mathrm{~L} / \mathrm{h}$. 


\subsection{Influences of operating conditions on the DCMD process performance}

353 The key operating conditions of the pilot DCMD regeneration of $\mathrm{LiCl}$ solutions include the 354 feed inlet temperature, the feed and distillate circulation rate, and the inlet $\mathrm{LiCl}$ concentration. The 355 distillate inlet temperature has less influence on the DCMD process performance; thus, it is fixed 356 at $25{ }^{\circ} \mathrm{C}$ in all simulations. The performance of the DCMD regeneration of $\mathrm{LiCl}$ solutions is 357 assessed using the process water flux $\left(J_{\text {process }}\right)$, thermal efficiency $\left(\Pi_{\text {process }}\right)$, specific thermal energy 358 consumption (STEC), and the increase in the $\mathrm{LiCl}$ concentration from the inlet to the outlet (i.e. $359 \Delta S$ ). While $S T E C$ is calculated using equation (11), $J_{\text {process }}$ and $\Pi_{\text {process }}$ are the average values of 360 local water flux $(J)$ and thermal efficiency $(\Pi)$ along the membrane leaf.

361 The simulation results reveal that it is beneficial to operate the pilot DCMD process of LiCl 362 solutions at higher feed inlet temperature and higher water circulation rates. As demonstrated in 363 Fig. 6A, elevating the feed inlet temperature boosts both $J_{\text {process }}$ and $\Pi_{\text {process }}$ while substantially 364 reducing STEC of the DCMD process. Increasing feed and distillate circulation rates also favours 365 the improvement of the $J_{\text {process }}$ and $\Pi_{\text {process }}$ and the reduction in STEC (Fig. 6B), but at a lower 366 extent compared to elevating the feed inlet temperature. Indeed, the benefits of operating the 367 DCMD process of $\mathrm{LiCl}$ solution at high feed inlet temperature and water circulation rates have 368 been proven in experimental works using lab-scale units (Duong et al. 2017; Duong et al. 2018). 369 The results reported here, however, highlight that even under the optimal feed inlet temperature 370 and water circulation rates, the pilot DCMD regeneration of $\mathrm{LiCl}$ solutions exhibits limited thermal 371 efficiency (i.e. $\Pi_{\text {process }}<0.5$ ) and discernibly high $S T E C$ (i.e. $\sim 100 \mathrm{kWh} /\left(\% \cdot \mathrm{m}^{3}\right)$ ). The poor thermal 372 efficiency of the DCMD process with the $\mathrm{LiCl}$ solution can be attributed to the hyper salinity of 373 the $\mathrm{LiCl}$ solution feed. 

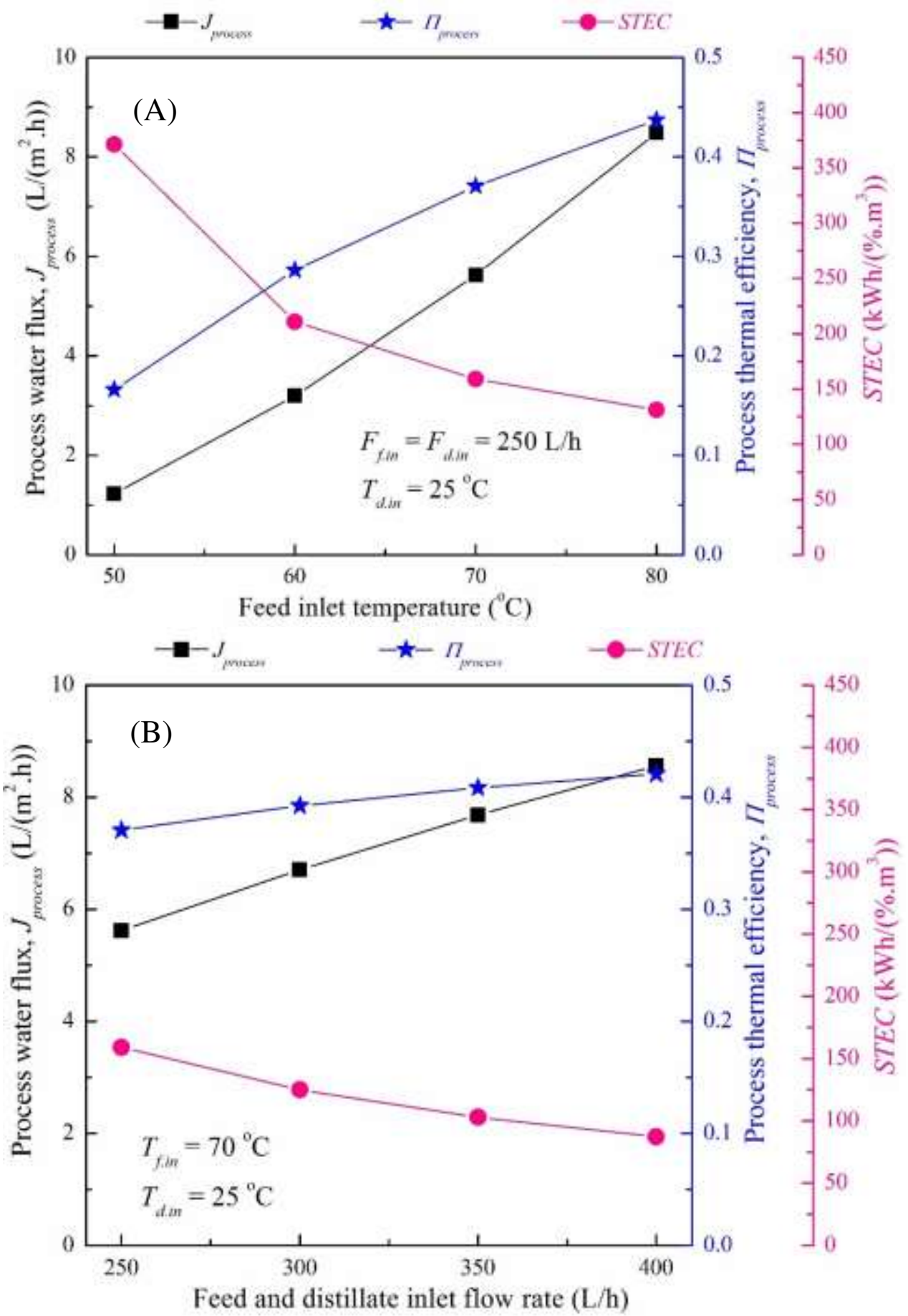

374 Fig. 6. The process water flux $\left(J_{\text {process }}\right)$, process thermal efficiency $\left(\Pi_{\text {process }}\right)$, and specific thermal energy consumption (STEC) of the DCMD regeneration of the $\mathrm{LiCl} 20 \%$ solution at (A) different feed inlet temperature and (B) different feed and distillate flow rate under counter-current flow.

Other operating conditions: distillate inlet temperature $T_{\text {d.in }}=25^{\circ} \mathrm{C}$.

379 7). When the inlet $\mathrm{LiCl}$ concentration is elevated from $20 \%$ to $30 \%, J_{\text {process }}$ reduces by $91 \%$ from 
3805.6 to $0.5 \mathrm{~L} /\left(\mathrm{m}^{2} \cdot \mathrm{h}\right)$, coinciding with a reduction in the $\Pi_{\text {process }}$ by $89 \%$ (i.e. from 0.37 to 0.04 ). The

$381 \mathrm{LiCl}$ concentration regulates not only the water vapour pressure but also the thermodynamic

382 properties (i.e. particularly the viscosity) of the feed solution, thus restraining the mass transfer

383 coefficient and water vapour flux through the membrane. Indeed, the simulation results reveal that

384 the dynamic viscosity of the $\mathrm{LiCl}$ solution doubles when the $\mathrm{LiCl}$ concentration is increased from

$38520 \%$ to $30 \%$. Previous experimental lab-scale works have demonstrated the strong impacts of the

386 feed concentration on water flux during the DCMD regeneration of $\mathrm{LiCl}$ solutions (Duong et al.

387 2017; Duong et al. 2018). These impacts are even more profound for the pilot DCMD process of

$388 \mathrm{LiCl}$ solutions given its much longer membrane leaf compared to that used in the lab-scale units.

389 The effects of membrane leaf length on the water flux and hence the thermal efficiency of the pilot

390 DCMD process with $\mathrm{LiCl}$ solution will be further elucidated in section 3.3. The limited water flux 391 and poor thermal efficiency inevitably leads to the discernibly high values of STEC at higher inlet $392 \mathrm{LiCl}$ concentration (Fig. 7).

393

394

395

396

397

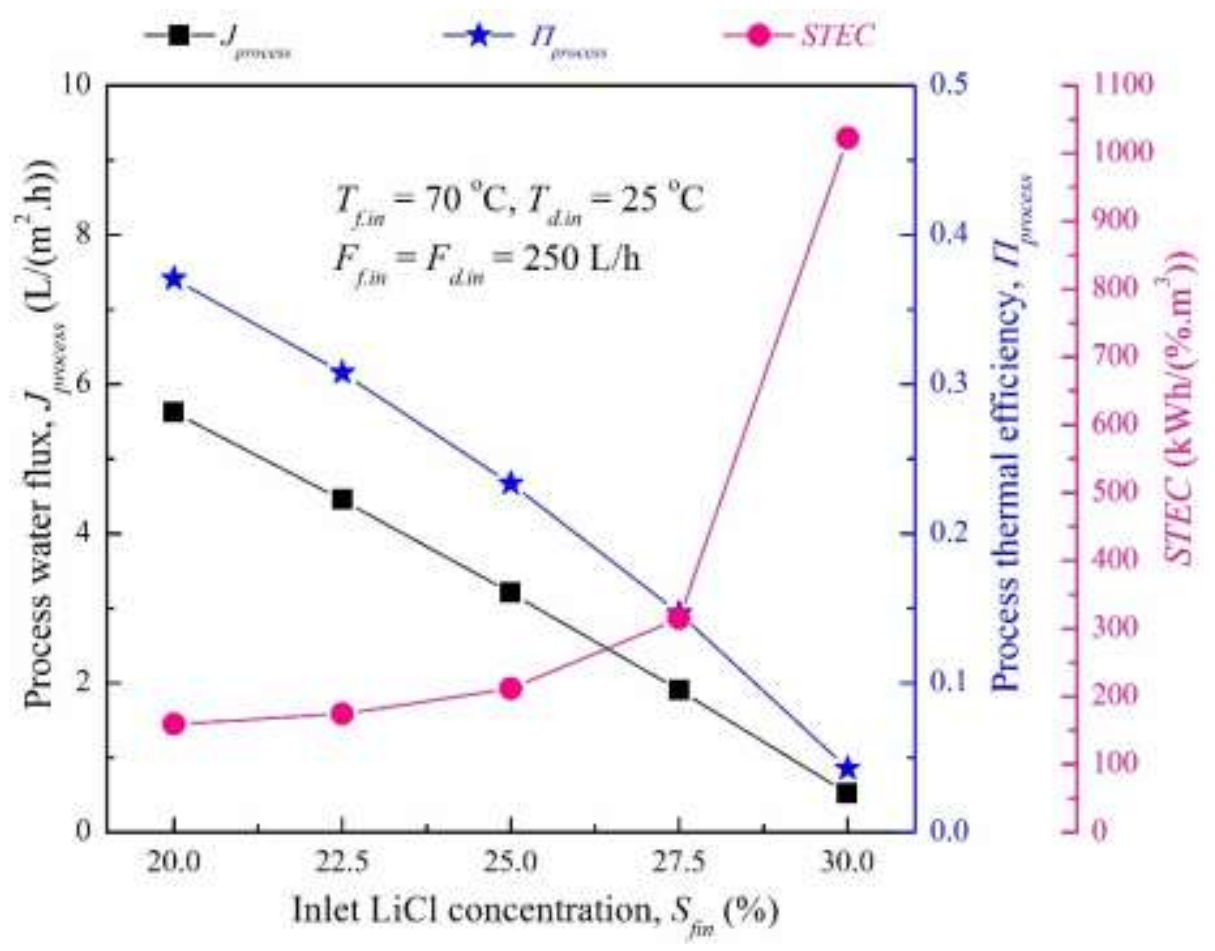

Fig. 7. The process water flux $\left(J_{\text {process }}\right)$, thermal efficiency $\left(\Pi_{\text {process }}\right)$, and specific thermal energy consumption (STEC) of the DCMD process of the $\mathrm{LiCl}$ solution at different concentration. Other operating conditions: feed inlet temperature $\left(T_{\text {fin }}\right)=70^{\circ} \mathrm{C}$, distillate inlet temperature $T_{\text {d.in }}=25$

${ }^{\circ} \mathrm{C}$, feed and distillate inlet circulation rate $F_{\text {f.in }}=F_{\text {d.in }}=250 \mathrm{~L} / \mathrm{h}$. 
398 Another important indicator for the performance of the DCMD regeneration of $\mathrm{LiCl}$ solutions 399 is the enrichment of $\mathrm{LiCl}$ in the feed (i.e. $\Delta S$ ). The three key operating conditions (e.g. feed inlet 400 temperature, water circulation rate, and the inlet $\mathrm{LiCl}$ concentration) exhibit different effects on $\Delta S$ 401 (Fig. 8). The feed inlet temperature is proportional with $\Delta S$ while elevating the LiCl solution 402 concentration noticeably reduces $\Delta S$ (Fig. 8A\&B). The impacts of feed inlet temperature and the $403 \mathrm{LiCl}$ concentration on $\Delta S$ appear similarly to their effects on water flux shown in Fig. 6A and Fig. 4047 . On the other hand, the feed and distillate circulation rates exert negligible impacts on $\Delta S$ despite 405 having a linear relationship with water flux (Fig. 6B). Unlike the feed inlet temperature and the $406 \mathrm{LiCl}$ concentration, the feed and distillate circulation rates determine the retention time of the $\mathrm{LiCl}$ 407 solution inside the membrane module. Increasing the water circulation rates enhances water flux 408 but also shortens the retention time of the $\mathrm{LiCl}$ solution feed. As a result, the impacts of the feed 409 and distillate circulation rates on $\Delta S$ seem to be neutralized (Fig. 8C).
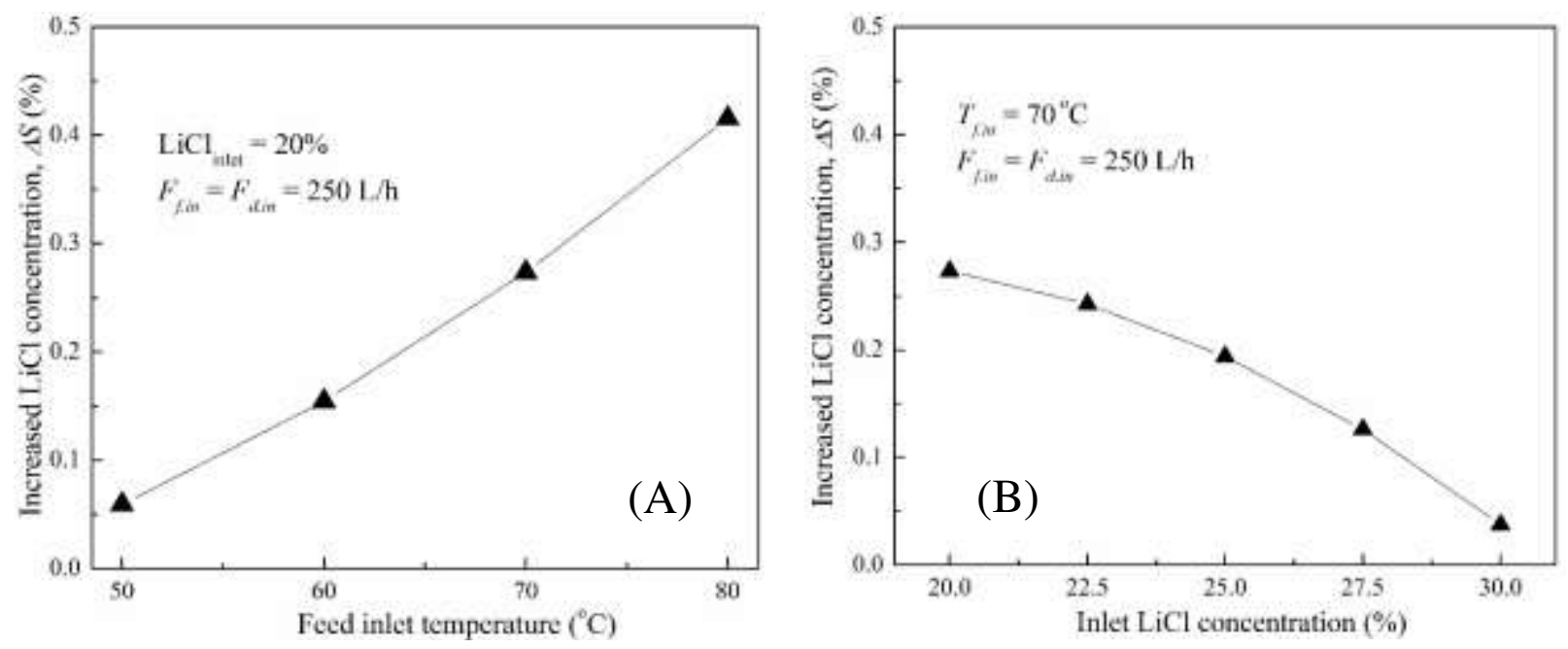


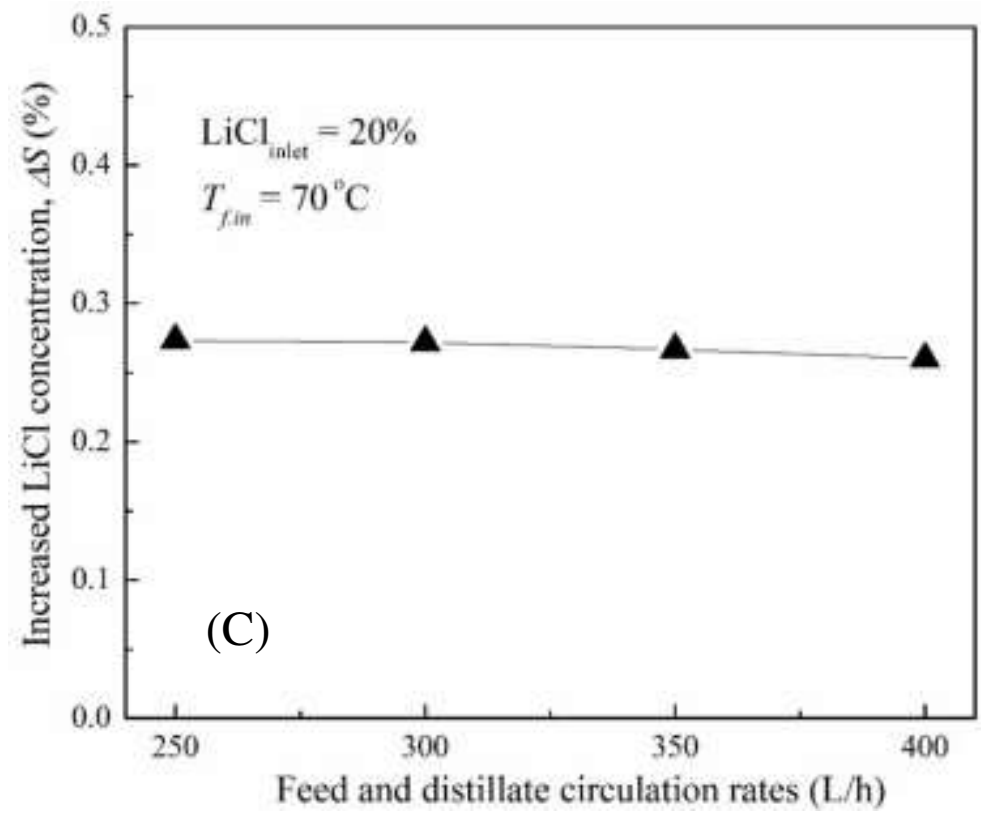

Fig. 8. The $\mathrm{LiCl}$ concentration enrichment achieved during the DCMD regeneration of the $\mathrm{LiCl}$ solution at various (A) feed inlet temperature, (B) inlet $\mathrm{LiCl}$ concentration, and (C) feed and distillate water circulation rates under counter-current flow. Other operating conditions: distillate inlet temperature $T_{\text {d.in }}=25^{\circ} \mathrm{C}$.

\subsection{Influences of the membrane length on the DCMD process performance}

Unlike experimental works using lab-scale units with fix membrane module specifications, the simulation in this study allows for systematically assessing the influences of membrane module specifications on the performance of the pilot DCMD regeneration of $\mathrm{LiCl}$ solutions. One of the most critical membrane module specifications for the pilot DCMD process is the membrane leaf length.

The simulation results reveal that the pilot DCMD process with $\mathrm{LiCl}$ solutions is more efficient when using a shorter membrane leaf (Fig. 9). The process with the shorter membrane leaf achieves higher water flux and thermal efficiency but lower STEC under the same operating conditions (e.g. feed inlet temperature, feed and distillate circulation rate, and inlet $\mathrm{LiCl}$ concentration). The enhanced process performance with the shortened membrane leaf can be attributed to the increased transmembrane temperature difference (i.e. $\Delta T_{m}$ ). For example, at the feed inlet and the distillate inlet temperatures of $70{ }^{\circ} \mathrm{C}$ and $25^{\circ} \mathrm{C}$, feed and distillate circulation rate of $250 \mathrm{~L} / \mathrm{h}$, and the inlet $\mathrm{LiCl}$ concentration of $20 \%$, the average $\Delta T_{m}$ of the process with the membrane length of $0.5 \mathrm{~m}$ and $1.5 \mathrm{~m}$ is $25.5^{\circ} \mathrm{C}$ and $17.1^{\circ} \mathrm{C}$, respectively. Given the exponential relation between the water vapour 
pressure and the temperature, the reduction in $\Delta T_{m}$ when increasing the membrane leaf length inevitably leads to the decline in water flux (Fig. 9). This decreasing water flux in turn negatively

431 affects thermal efficiency ( $\left.\Pi_{\text {process }}\right)$ and hence raises the $S T E C$ of the process.

The results reported here have important implications to the design of the membrane modules 433 destined for liquid desiccant air-conditioning applications. Membrane modules with longer 434 membrane leaves offer larger membrane areas for water evaporation and hence achieve a higher $435 \mathrm{LiCl}$ concentration at the outlet of the membrane modules. However, the process using longer membrane exhibits lower water flux and thermal efficiency as discussed above. Therefore, for the

437 pilot DCMD regeneration of liquid desiccant solutions, it is more beneficial to deploy membrane 438 modules with short membrane leaves. The process can be operated in batch mode or brine recycling 439 mode (i.e. whereby the brine leaving the membrane modules is returned to the feed tank for further 440 treatment cycles) (Duong et al. 2015; Duong et al. 2017). Operating under these modes, the LiCl 441 concentration can be achieved without compromising the water flux and thermal efficiency of the 442 pilot DCMD process.

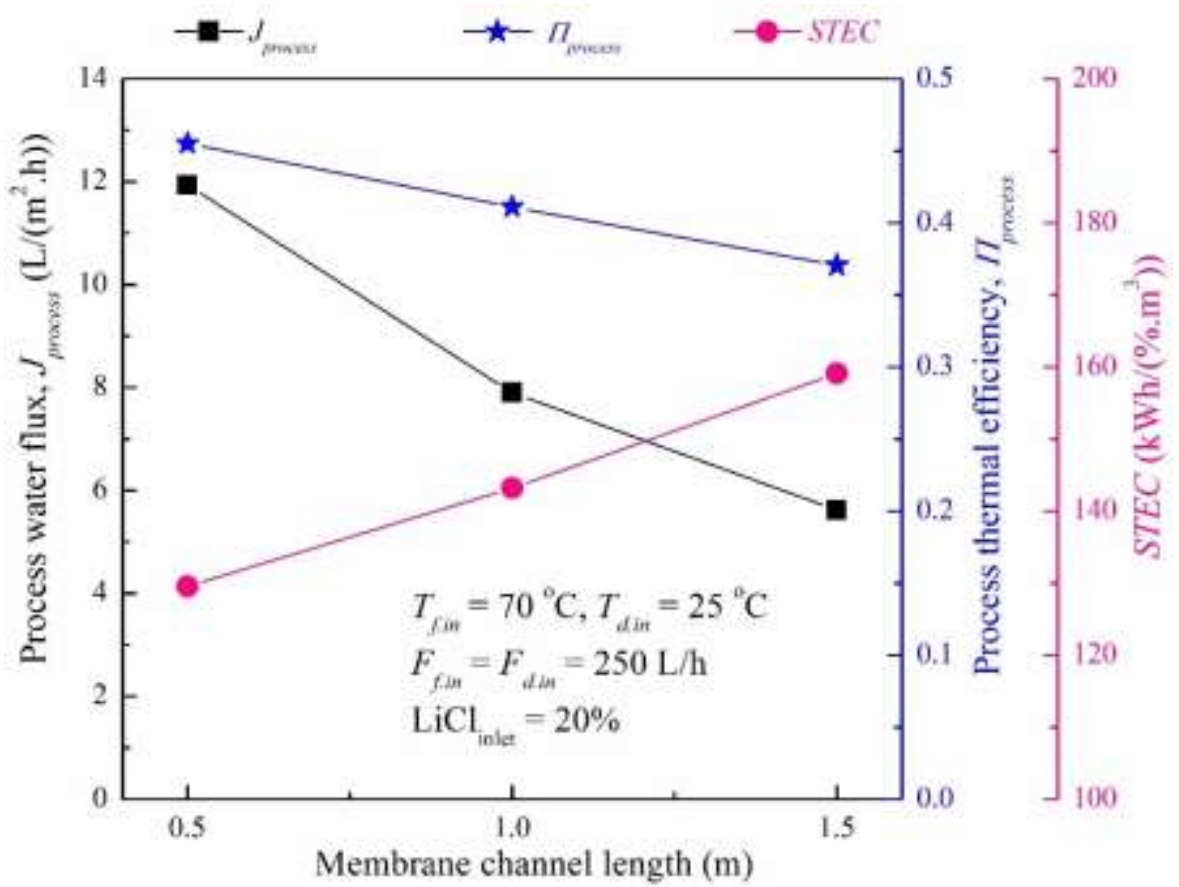

Fig. 9. The process water flux $\left(J_{\text {process }}\right)$, thermal efficiency $\left(\Pi_{\text {process }}\right)$, and specific thermal energy consumption (STEC) of the pilot DCMD regeneration of the $\mathrm{LiCl} 20 \%$ solution using the membrane module with different membrane length. Other operating conditions: feed inlet temperature $\left(T_{\text {f.in }}\right)=70^{\circ} \mathrm{C}$, distillate inlet temperature $T_{\text {d.in }}=25^{\circ} \mathrm{C}$, feed and distillate inlet circulation rate $F_{\text {f.in }}=F_{\text {d.in }}=250 \mathrm{~L} / \mathrm{h}$. 


\section{Conclusions}

450 This study assesses the pilot DCMD regeneration of liquid desiccant $\mathrm{LiCl}$ solution in LDAC 451 systems using computer simulation. In contrast to experimental investigations, the simulation 452 allows for the insightful evaluation of the heat and mass transfer through the membrane inside the

453 DCMD membrane module as it can incorporate both temperature and concentration polarisation 454 effects in the calculation of heat and water flux. The simulation results demonstrate that the flow 455 mode of the pilot DCMD process strongly affects the heat and mass transfer across the membrane, 456 and the counter-current flow mode is more beneficial than co-current one regarding the process 457 water flux, thermal efficiency, and $\mathrm{LiCl}$ concentration enrichment. Moreover, when operating the 458 pilot DCMD process of $\mathrm{LiCl}$ solution under the counter-current flow, the feed inlet temperature,

459 the feed $\mathrm{LiCl}$ concentration, and particularly the membrane leaf length are significant factors 460 governing the process performance. When increasing the membrane leaf length from 0.5 to $1.5 \mathrm{~m}$, 461 the process water flux decreases by a half from 12 to $6 \mathrm{~L} /\left(\mathrm{m}^{2} \cdot \mathrm{h}\right)$ and thermal efficiency decreases 462 by $20 \%$. These simulation results have important implications to the design of the pilot DCMD 463 membrane modules, particularly the membrane leaf length.

\section{Acknowledgements}

465 This research is funded by Vietnam National Foundation for Science and Technology 466 Development (NAFOSTED) under the grant number 105.08-2019.08.

\section{References}

468 Abdelkader S, Gross F, Winter D, Went J, Koschikowski J, Geissen SU, and Bousselmi L (2019) 469 Application of direct contact membrane distillation for saline dairy effluent treatment: performance 470 and fouling analysis. Environ. Sci. Pollut. Res. 26:18979-18992.

471 Alkhudhiri A, Darwish N, and Hilal N (2012) Membrane distillation: A comprehensive review. 472 Desalination 287:2-18.

473 Andrés-Mañas JA, Roca L, Ruiz-Aguirre A, Acién FG, Gil JD, and Zaragoza G (2020) Application 474 of solar energy to seawater desalination in a pilot system based on vacuum multi-effect membrane 475 distillation. Appl. Energy 258:114068. 
Andrés-Mañas JA, Ruiz-Aguirre A, Acién FG, and Zaragoza G (2018) Assessment of a pilot system for seawater desalination based on vacuum multi-effect membrane distillation with enhanced heat recovery. Desalination 443:110-121.

479 Anvari A, Azimi Yancheshme A, Kekre KM, and Ronen A (2020) State-of-the-art methods for 480 overcoming temperature polarization in membrane distillation process: A review. J. Membr. Sci. 481 616:118413.

Bindels M, Carvalho J, Gonzalez CB, Brand N, and Nelemans B (2020) Techno-economic assessment of seawater reverse osmosis (SWRO) brine treatment with air gap membrane distillation (AGMD). Desalination 489:114532.

485 Chen X, Riffat S, Bai H, Zheng X, and Reay D (2020) Recent progress in liquid desiccant 486 dehumidification and air-conditioning: A review. Energ. Built Environ. 1:106-130.

487 Cheng Q and Zhang X (2013) Review of solar regeneration methods for liquid desiccant air488

489 Conde MR (2004) Properties of aqueous solutions of lithium and calcium chlorides: formulations 490 for use in air conditioning equipment design. Int. J. Therm. Sci. 43:367-382.

491 Dong G, Kim JF, Kim JH, Drioli E, and Lee YM (2017) Open-source predictive simulators for 492 scale-up of direct contact membrane distillation modules for seawater desalination. Desalination 493 402:72-87.

494 Duong HC, Álvarez IRC, Nguyen TV, and Nghiem LD (2018) Membrane distillation to regenerate 495 different liquid desiccant solutions for air conditioning. Desalination 443:137-142.

496 Duong HC, Ansari AJ, Cao HT, Nguyen NC, Do KU, and Nghiem LD (2020) Membrane 497 distillation regeneration of liquid desiccant solution for air-conditioning: Insights into polarisation 498 effects and mass transfer. Environ. Technolo. Inno. 19:100941.

499 Duong HC, Ansari AJ, Nghiem LD, Cao HT, Vu TD, and Nguyen TP (2019) Membrane Processes 500 for the Regeneration of Liquid Desiccant Solution for Air Conditioning. Curr. Pollut. Rep. 5:308501318.

502 Duong HC, Cooper P, Nelemans B, Cath TY, and Nghiem LD (2015) Optimising thermal 503 efficiency of direct contact membrane distillation by brine recycling for small-scale seawater 504 desalination. Desalination 374:1-9.

505 Duong HC, Hai FI, Al-Jubainawi A, Ma Z, He T, and Nghiem LD (2017) Liquid desiccant lithium 506 chloride regeneration by membrane distillation for air conditioning. Sep. Purif. Technol. 177:121507128.

508 Duong HC, Pham TM, Luong ST, Nguyen KV, Nguyen DT, Ansari AJ, and Nghiem LD (2019) A 509 novel application of membrane distillation to facilitate nickel recovery from electroplating 510 wastewater. Environ. Sci. Pollut. Res. 26:23407-23415. 
511 Duong HC, Xia L, Ma Z, Cooper P, Ela W, and Nghiem LD (2017) Assessing the performance of 512 solar thermal driven membrane distillation for seawater desalination by computer simulation. J. 513 Membr. Sci. 542:133-142.

514 Gurubalan A, Maiya MP, and Geoghegan PJ (2019) A comprehensive review of liquid desiccant 515 air conditioning system. Appl. Energy 254:113673.

516 Hitsov I, Eykens L, Schepper WD, Sitter KD, Dotremont C, and Nopens I (2017) Full-scale direct 517 contact membrane distillation (DCMD) model including membrane compaction effects. J. Membr. 518 Sci. 524:245-256.

519 Hitsov I, Maere T, De Sitter K, Dotremont C, and Nopens I (2015) Modelling approaches in 520 membrane distillation: A critical review. Sep. Purif. Technol. 142:48-64.

521 Khayet M, Velázquez A, and Mengual JI (2004) Modelling mass transport through a porous 522 partition: Effect of pore size distribution. J. Non-Equil. Thermody. 29:279-299.

523 Kuang Z, Long R, Liu Z, and Liu W (2019) Analysis of temperature and concentration 524 polarizations for performance improvement in direct contact membrane distillation. Int. J. Heat 525 Mass Tran. 145:118724.

526 Lefers R, Bettahalli NMS, Fedoroff N, Nunes SP, and Leiknes T (2018) Vacuum membrane 527 distillation of liquid desiccants utilizing hollow fiber membranes. Sep. Purif. Technol. 199:57-63.

528 Liu J, Ren H, Hai FI, Albdoor AK, and Ma Z (2021) Direct contact membrane distillation for liquid desiccant regeneration and fresh water production: Experimental investigation, response surface 530 modeling and optimization. Appl. Therm. Eng. 184:116293.

531 Lokare OR, Ji P, Wadekar S, Dutt G, and Vidic RD (2019) Concentration polarization in membrane 532 distillation: I. Development of a laser-based spectrophotometric method for in-situ 533 characterization. J. Membr. Sci. 581:462-471.

534 Lowenstein A (2008) Review of Liquid Desiccant Technology for HVAC Applications. HVAC\&R 535 Research 14:819-839.

536 Modi KV and Shukla DL (2018) Regeneration of liquid desiccant for solar air-conditioning and 537

538 Nguyen NC, Chen S-S, Jain S, Nguyen HT, Ray SS, Ngo HH, Guo W, Lam NT, and Duong HC 539 (2018) Exploration of an innovative draw solution for a forward osmosis-membrane distillation 540 desalination process. Environ. Sci. Pollut. Res. 25:5203-5211.

541 Salikandi M, Ranjbar B, Shirkhan E, Shanmuga Priya S, Thirunavukkarasu I, and Sudhakar K 542 (2021) Recent trends in liquid desiccant materials and cooling systems: Application, performance 543 and regeneration characteristics. J. Build. Eng. 33:101579.

544 Yan Z, Yang H, Qu F, Yu H, Liang H, Li G, and Ma J (2017) Reverse osmosis brine treatment 545 using direct contact membrane distillation: Effects of feed temperature and velocity. Desalination 546 423:149-156. 
547 Zhou J, Noor N, Wang F, and Zhang X (2020) Simulation and experiment on direct contact 548 membrane distillation regenerator in the liquid dehumidification air-conditioning system. Build. 549 Environ. 168:106496.

550 Zhou J, Wang F, Noor N, and Zhang X (2020) An experimental study on liquid regeneration 551 process of a liquid desiccant air conditioning system (LDACs) based on vacuum membrane 552 distillation. Energy 194:116891.

553 Zhou J, Zhang X, Su W, and Sun B (2019) Performance analysis of vacuum membrane distillation 554 regenerator in liquid desiccant air conditioning system. Int. J. Refrig.102:112-121. 
Figures
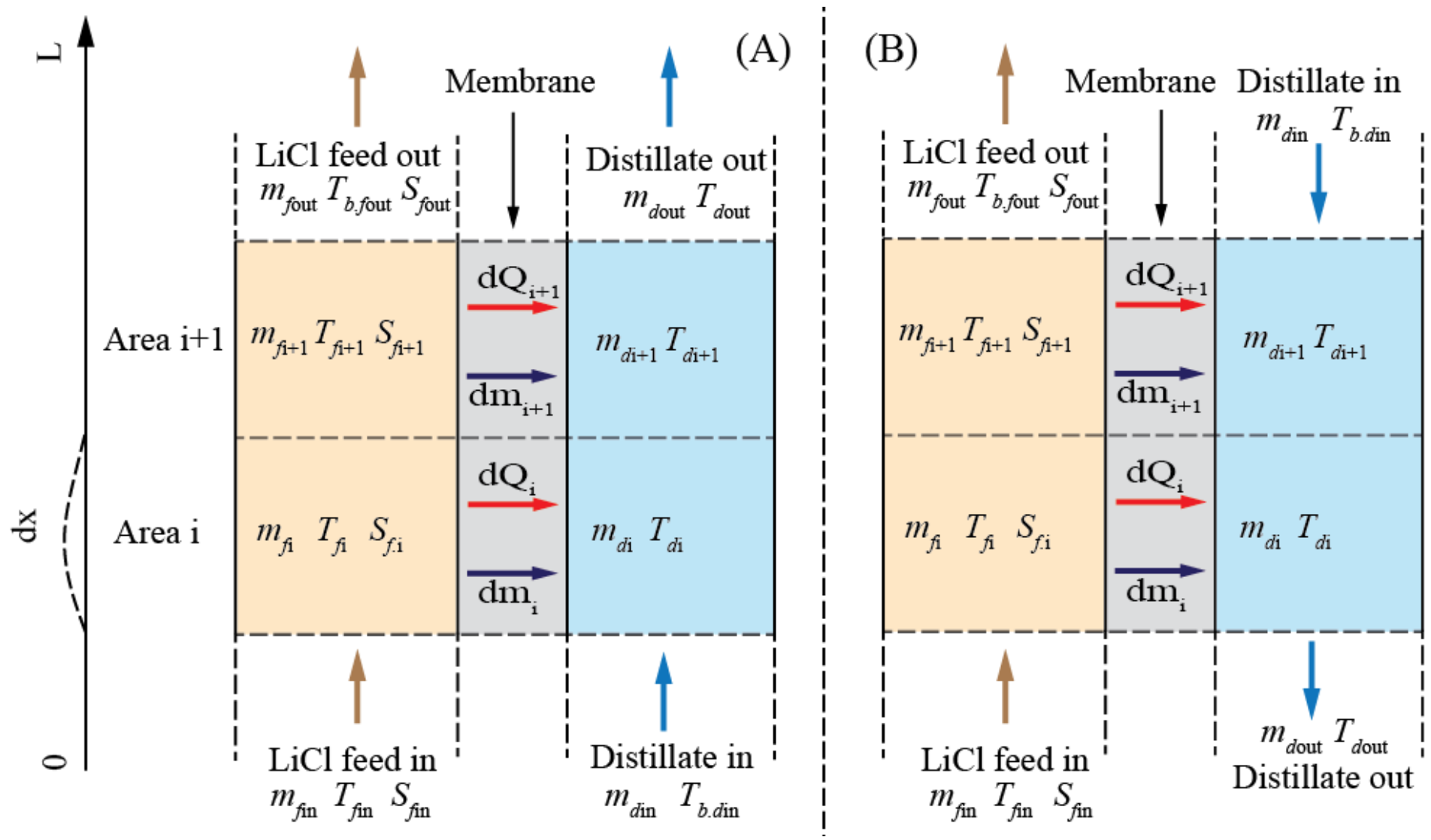

Figure 1

Schematic diagram of two incremental membrane areas along the DCMD module under the $(A)$ cocurrent and (B) counter-current flow mode. 


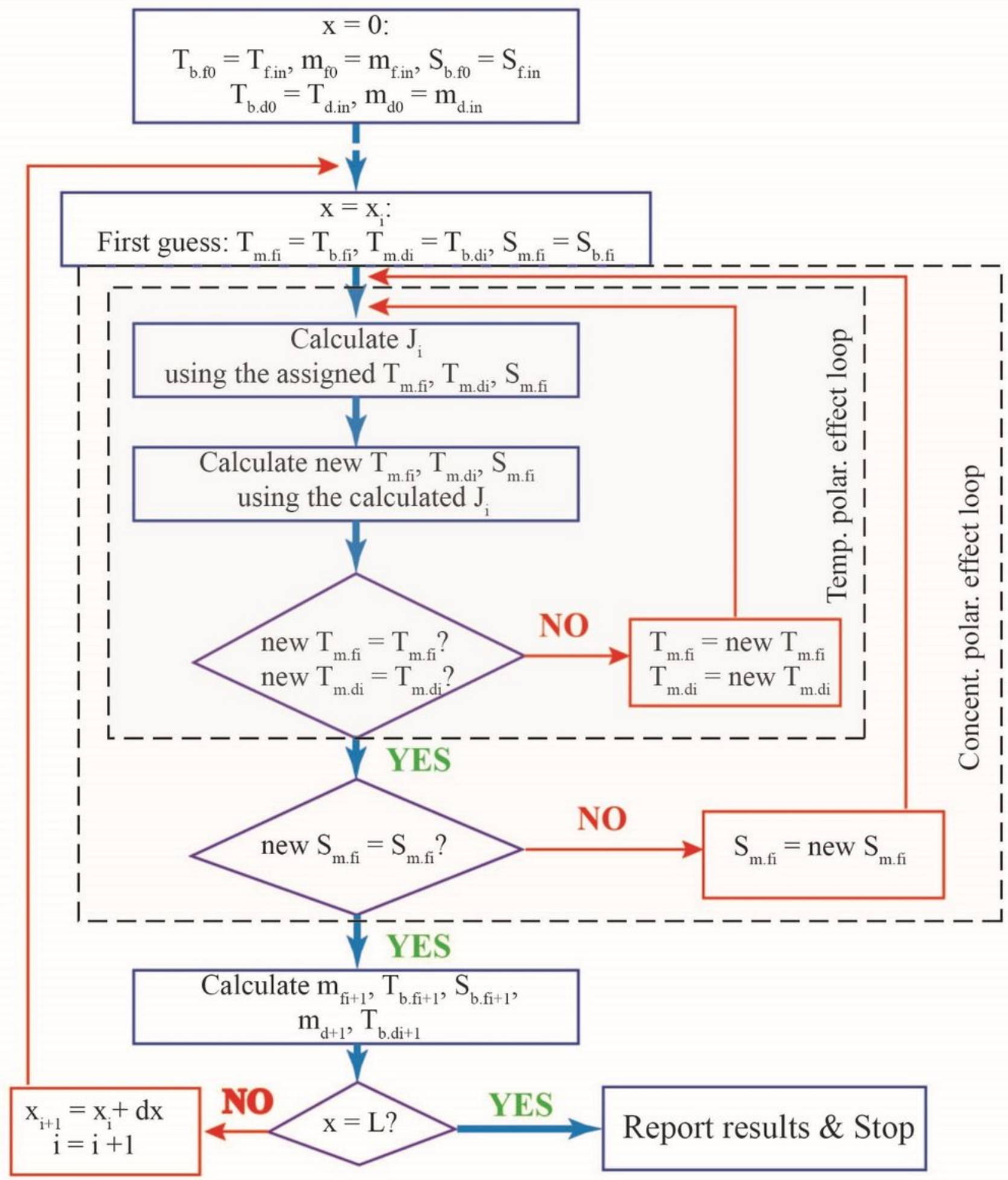

Figure 2

Calculation algorithm of the DCMD simulation for co-current flow. 


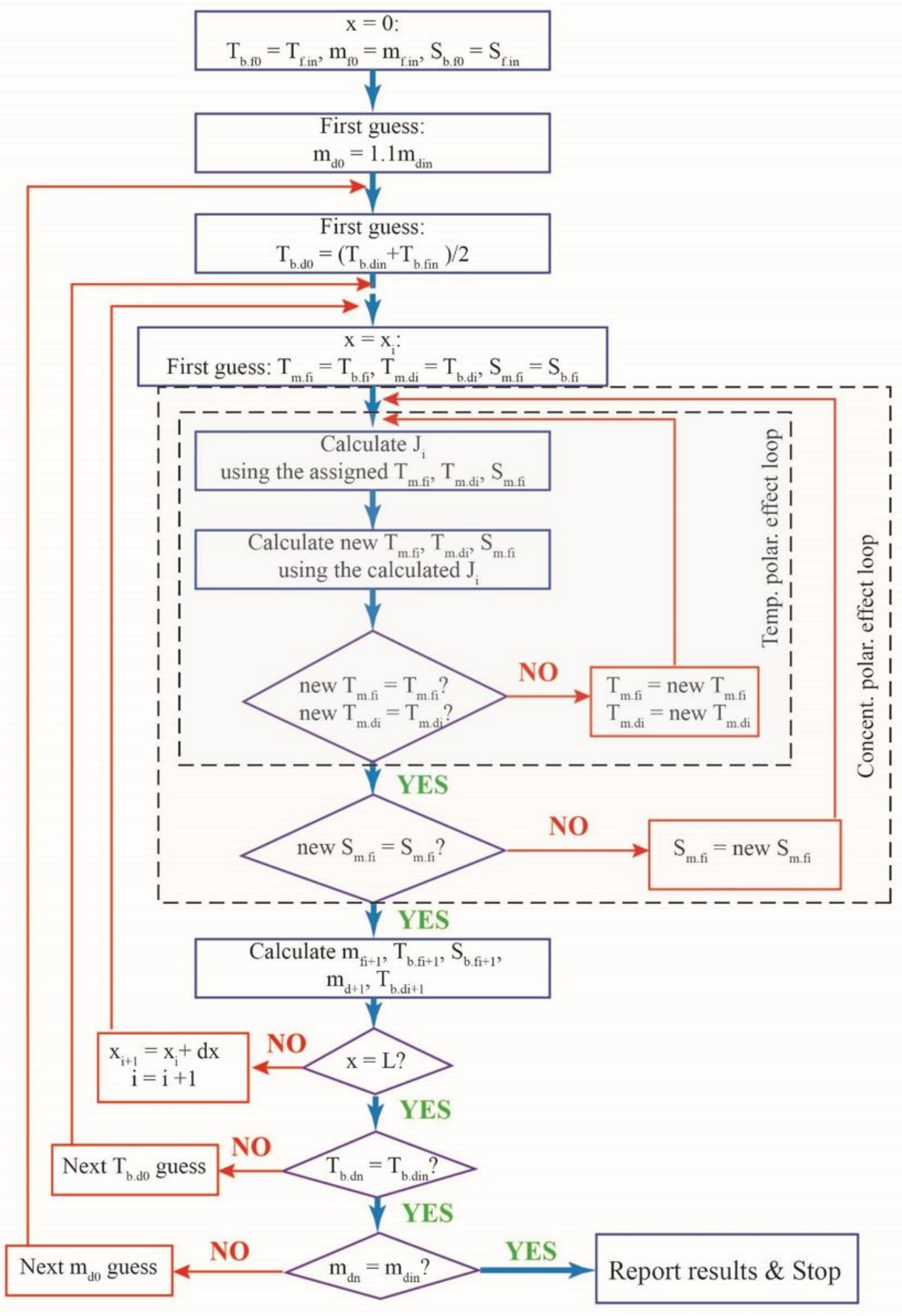

Figure 3

Calculation algorithm of the DCMD simulation for counter-current flow. 

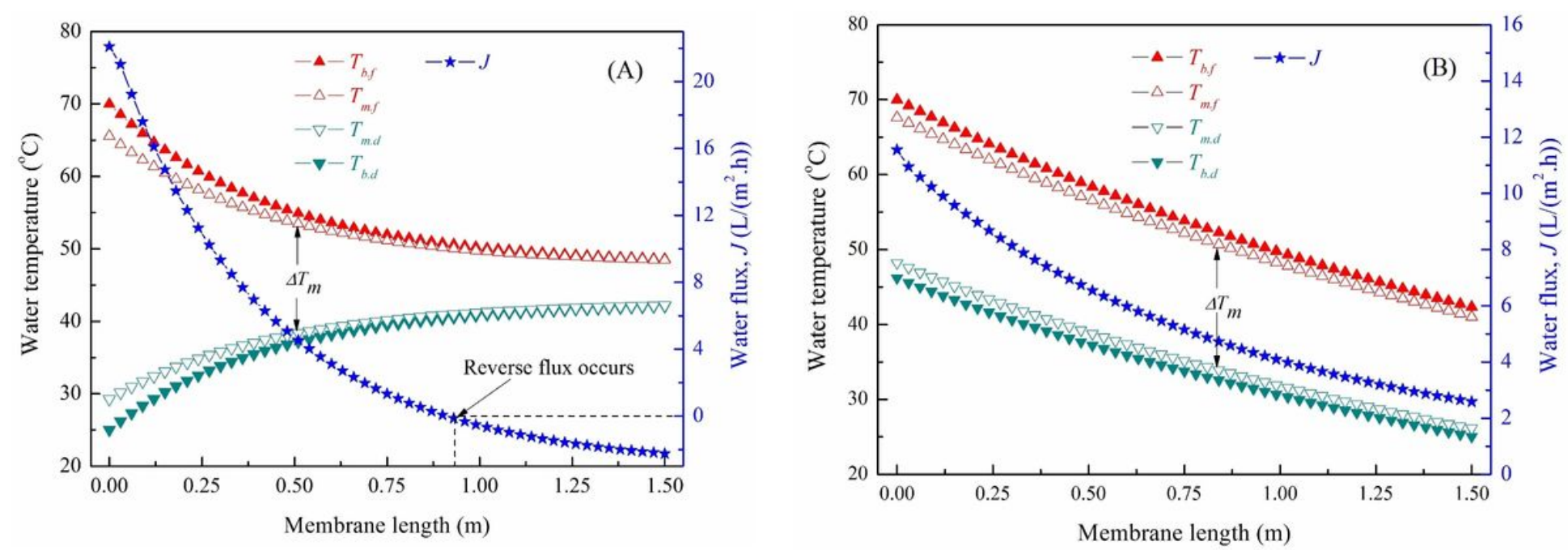

Figure 4

Feed and distillate temperature at the membrane surfaces and in the bulk streams and water flux along the membrane inside the module during the DCMD regeneration of the $\mathrm{LiCl} 20 \%$ solution under $(\mathrm{A}) \mathrm{co}$ current and (B) counter-current flow. Operating conditions: feed inlet temperature (Tf.in) $=70$ oC, distillate inlet temperature Td.in $=25 \mathrm{oC}$, feed and distillate inlet circulation rate Ff.in $=\mathrm{Fd}$. in $=250 \mathrm{~L} / \mathrm{h}$.

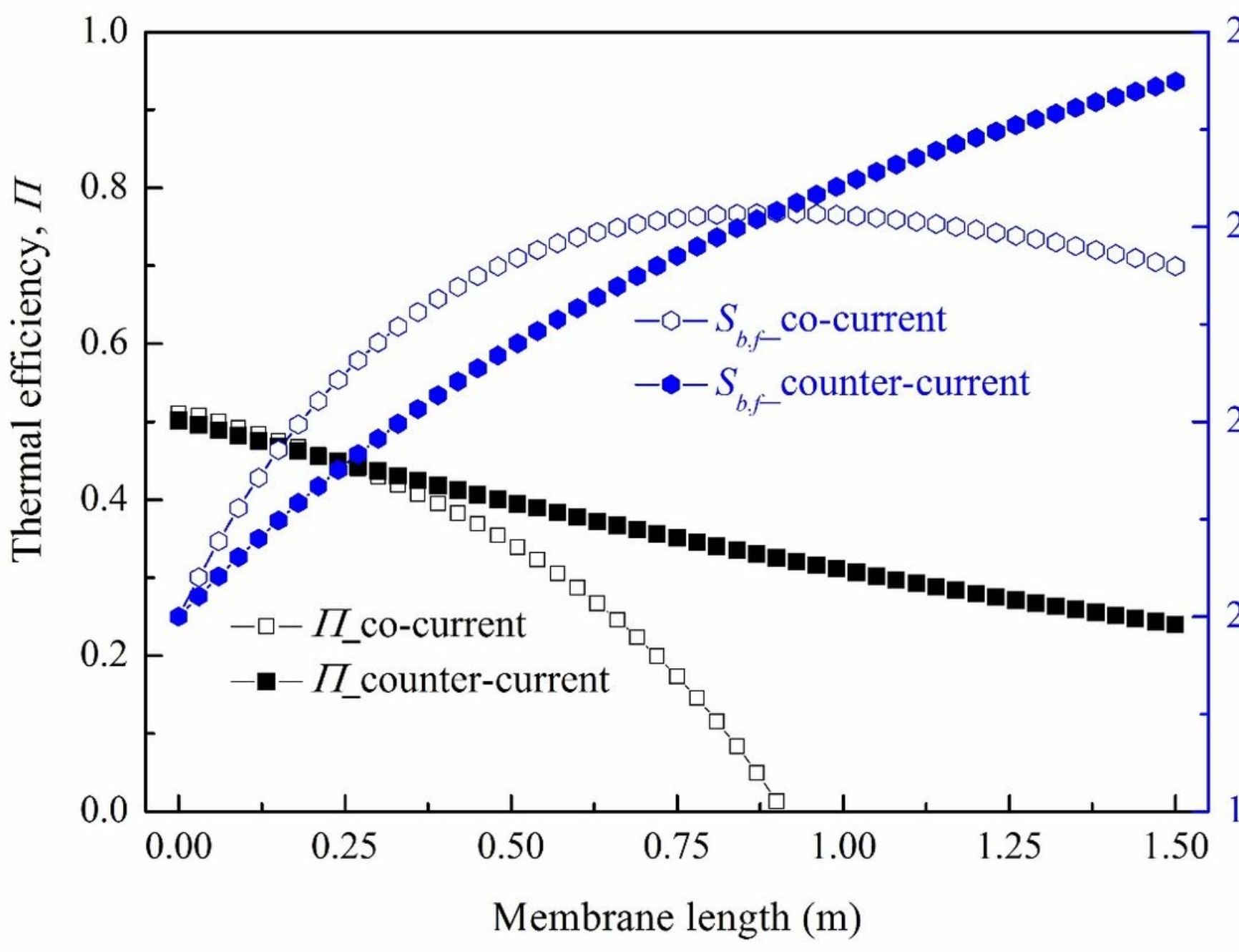

20.3 


\section{Figure 5}

Thermal efficiency and the bulk $\mathrm{LiCl}$ concentration along the membrane inside the module during the DCMD regeneration of the $\mathrm{LiCl} 20 \%$ solution under co-current and counter-current flow. Operating conditions: feed inlet temperature $(T f . i n)=70 \mathrm{C}$, distillate inlet temperature Td.in $=25 \mathrm{oC}$, feed and distillate inlet circulation rate Ff.in $=\mathrm{Fd}$.in $=250 \mathrm{~L} / \mathrm{h}$.
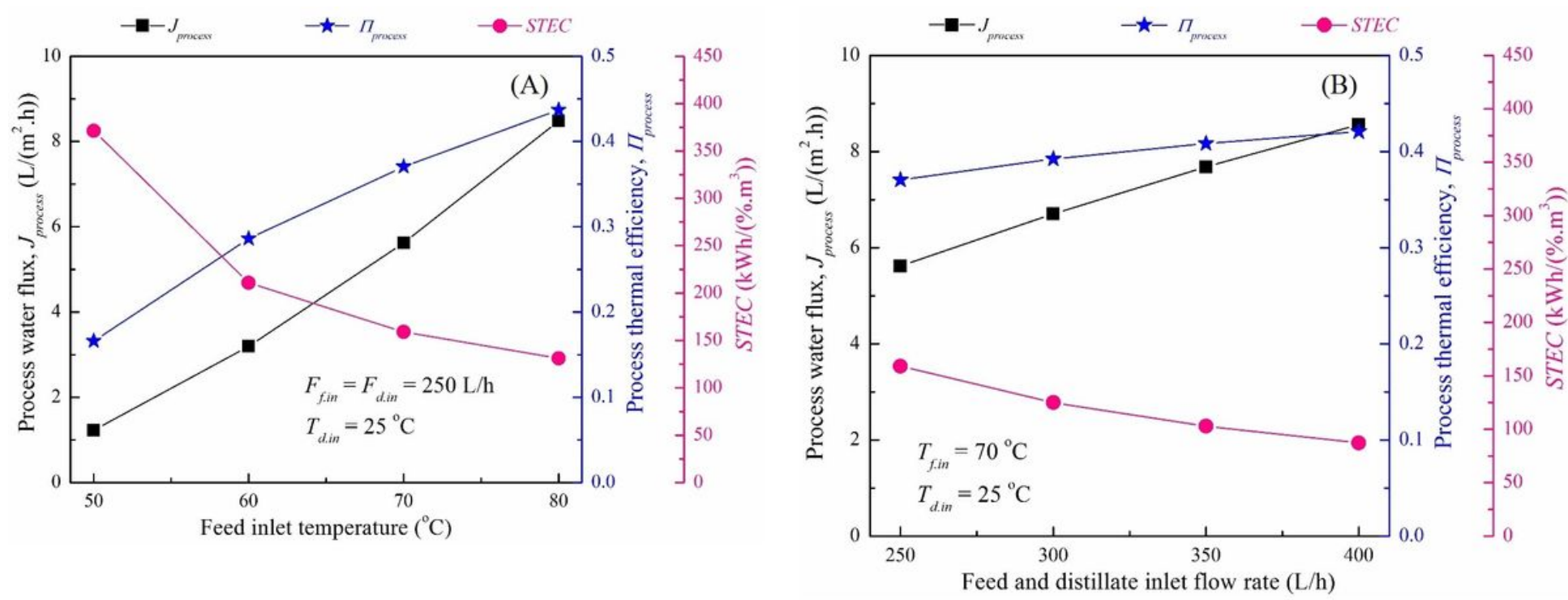

Figure 6

The process water flux (Jprocess), process thermal efficiency (Ilprocess), and specific thermal energy consumption (STEC) of the DCMD regeneration of the $\mathrm{LiCl} 20 \%$ solution at (A) different feed inlet temperature and (B) different feed and distillate flow rate under counter-current flow. Other operating conditions: distillate inlet temperature Td.in $=250 \mathrm{C}$. 


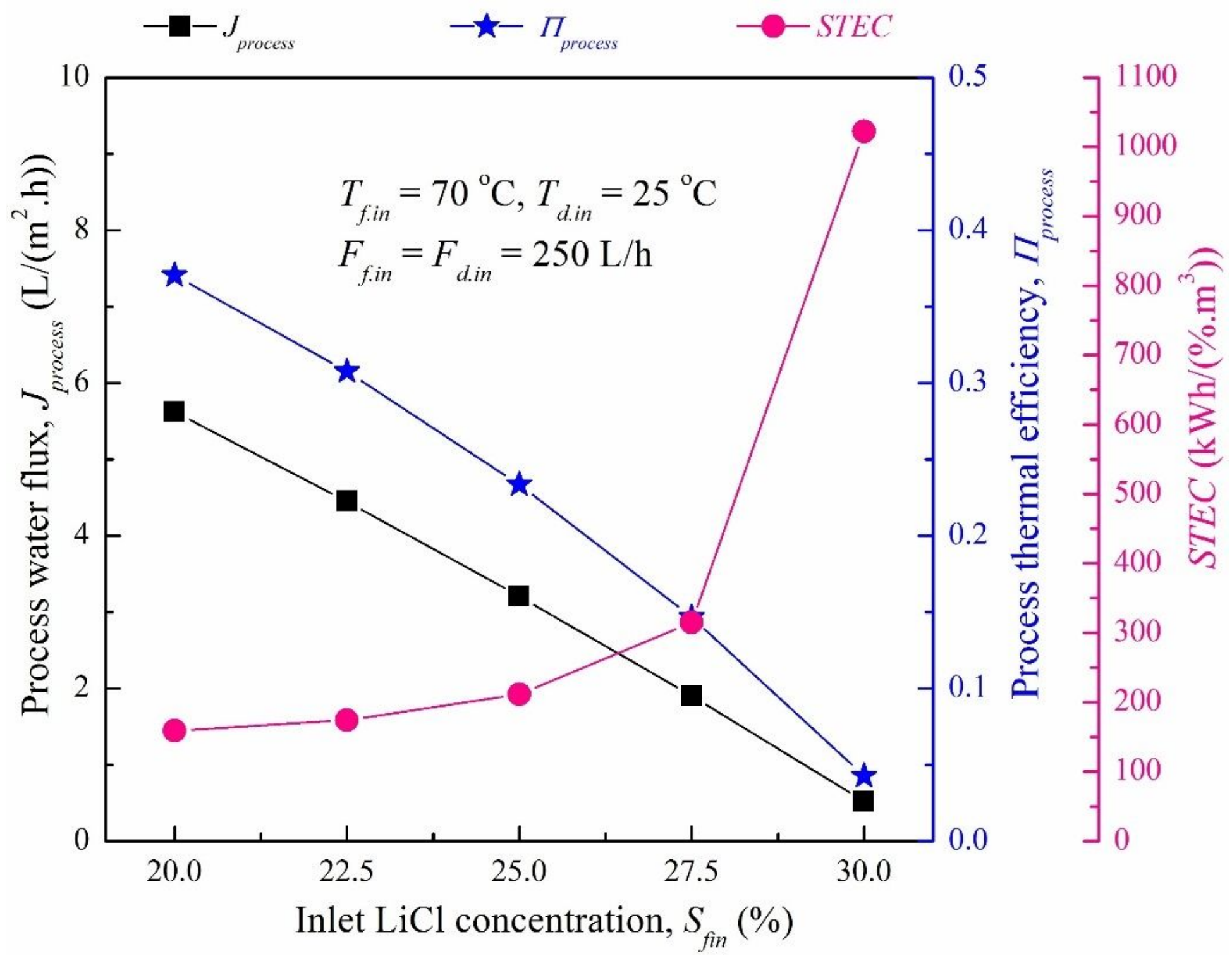

Figure 7

The process water flux (Jprocess), thermal efficiency (Ilprocess), and specific thermal energy consumption (STEC) of the DCMD process of the LiCl solution at different concentration. Other operating conditions: feed inlet temperature (Tf.in) $=70 \mathrm{oC}$, distillate inlet temperature Td.in $=25 \mathrm{oC}$, feed and distillate inlet circulation rate Ff.in $=\mathrm{Fd}$.in $=250 \mathrm{~L} / \mathrm{h}$. 

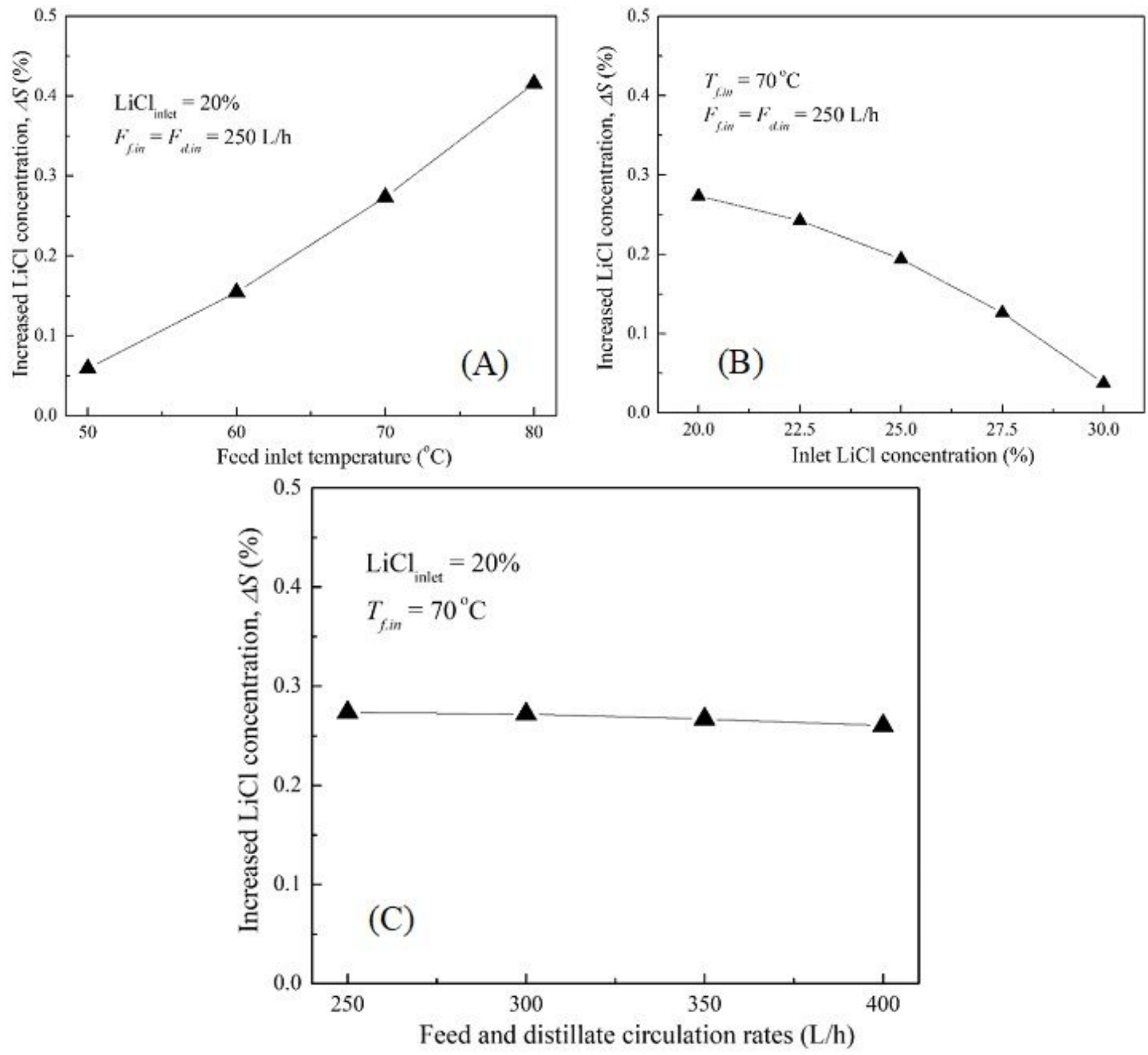

Figure 8

The $\mathrm{LiCl}$ concentration enrichment achieved during the DCMD regeneration of the $\mathrm{LiCl}$ solution at various (A) feed inlet temperature, (B) inlet $\mathrm{LiCl}$ concentration, and (C) feed and distillate water circulation rates under counter-current flow. Other operating conditions: distillate inlet temperature Td.in $=25 \mathrm{oC}$. 


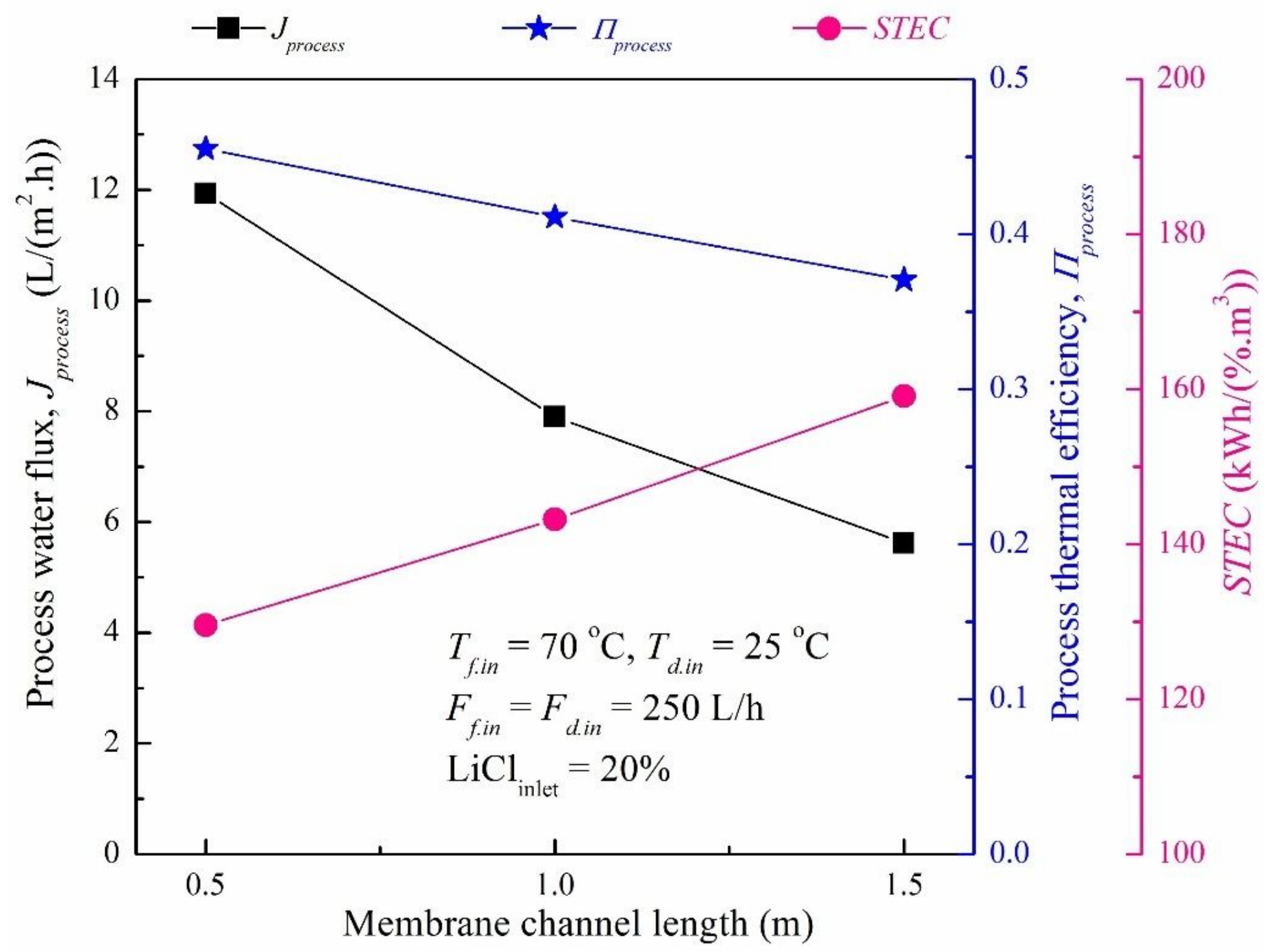

Figure 9

The process water flux (Jprocess), thermal efficiency ( $\square$ process), and specific thermal energy consumption (STEC) of the pilot DCMD regeneration of the $\mathrm{LiCl} 20 \%$ solution using the membrane module with different membrane length. Other operating conditions: feed inlet temperature ( $T f$.in $)=70$ $\mathrm{oC}$, distillate inlet temperature Td.in $=25 \mathrm{oC}$, feed and distillate inlet circulation rate Ff.in $=$ Fd.in $=250$ L/h. 